Phase II Environmental Geophysics at J-Field,

$$
\begin{array}{r}
\text {-IVEO } \\
\text { WIIV }-71995 \\
S T I
\end{array}
$$
Aberdeen Proving Ground, Maryland

Energy Systems Division Argonne National Laboratory

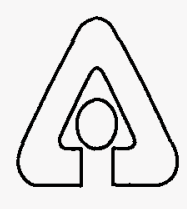

Operated by The University of Chicago, under Contract W-31-109-Eng-38, for the

United States Department of Energy

DISTRIBUTION OF THIS DOCUMENT IS UNLIMTED 


\section{Argonne National Laboratory}

Argonne National Laboratory, with facilities in the states of Illinois and Idaho, is owned by the United States Government, and operated by the University of Chicago under the provisions of a contract with the Department of Energy.

This technical memo is a product of Argonne's Energy Systems (ES) Division. For information on the division's scientific and engineering activities, contact:

Director, Energy Systems Division

Argonne National Laboratory

Argonne, Illinois 60439-4815

Telephone (708) 252-3724

Presented in this technical memo are preliminary results of ongoing work or work that is more limited in scope and depth than that described in formal reports issued by the ES Division.

Publishing support services were provided by Argonne's Information and Publishing Division.

\section{Disclaimer}

This report was prepared as an account of work sponsored by an agency of the United States Government. Neither the United States Government nor any agency thereof, nor any of their employees, makes any warranty, express or implied, or assumes any legal liability or responsibility for the accuracy, completeness, or usefulness of any information, apparatus, product, or process disclosed, or represents that its use would not infringe privately owned rights. Reference herein to any specific commercial product, process, or service by trade name, trademark, manufacturer, or otherwise, does not necessarily constitute or imply its endorsement, recommendation, or favoring by the United States Government or any agency thereof. The views and opinions of authors expressed herein do not necessarily state or reflect those of the United States Government or any agency thereof. 


\section{DISCLAIMER}

Portions of this document may be illegible in electronic image products. Images are produced from the best available original document. 


\section{Phase II Environmental Geophysics at J-Field, Aberdeen Proving Ground, Maryland}

B.E. Davies, M.D. Thompson, C.R. Yuen, J.E. Stefanov, G.J. Kuecher, M.A. Benson, C.A. Padar, and L.D. McGinnis

Center for Environmental Restoration Systems, Energy Systems Division,

Argonne National Laboratory, 9700 South Cass Avenue, Argonne, Illinois 60439

Work sponsored by United States Department of Defense, United States Army, Aberdeen Proving Ground, Maryland 
This report is printed on recycled paper. 


\section{Contents}

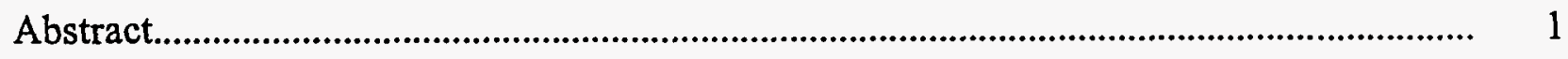

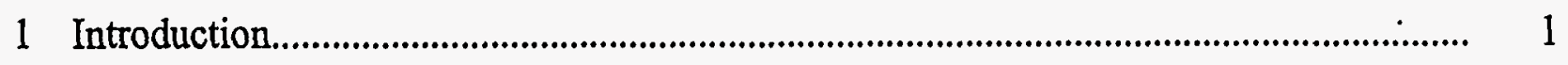

1.1 Physiographic Setting and Site Survey................................................................ 4

1.2 Geology and Hydrogeology ............................................................................... 5

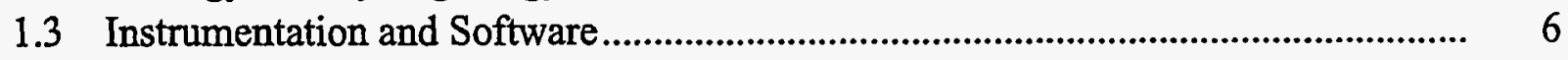

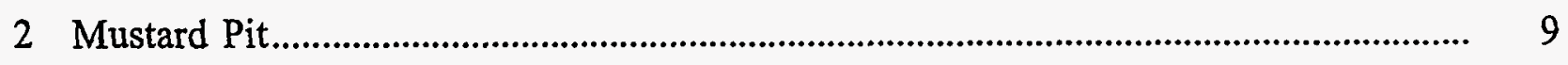

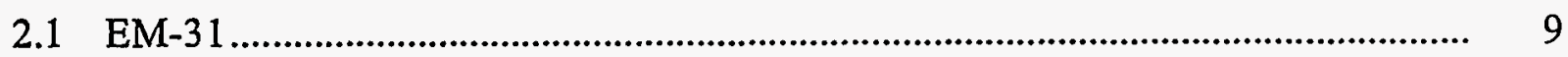

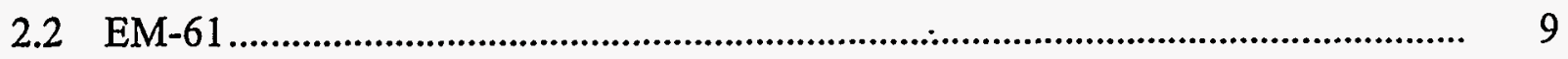

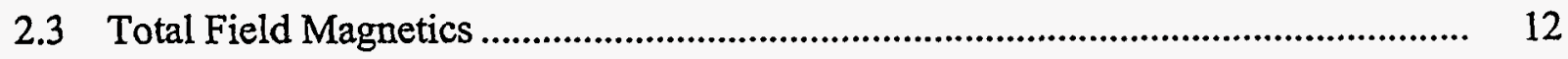

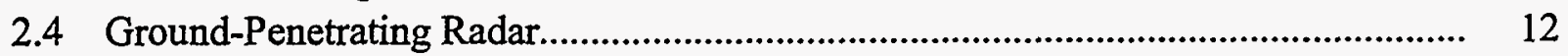

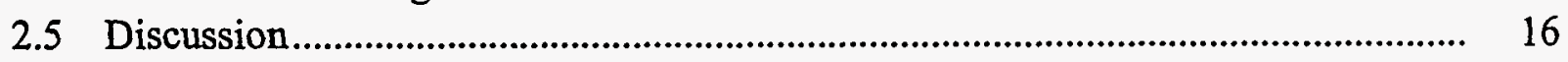

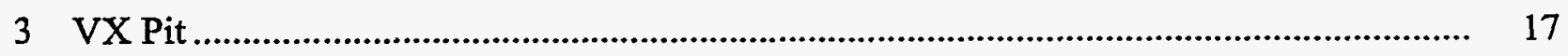

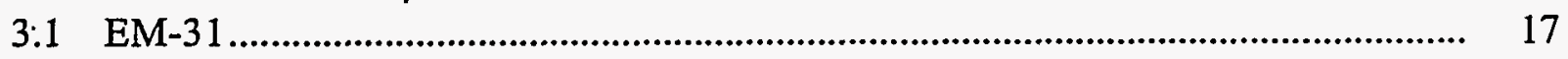

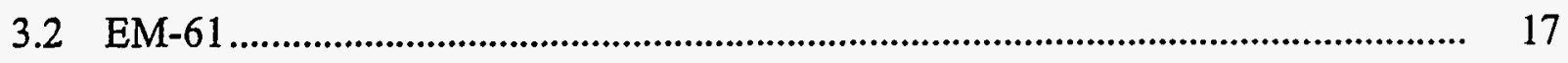

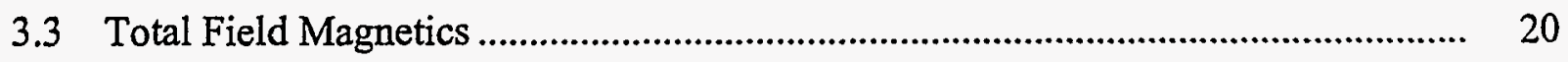

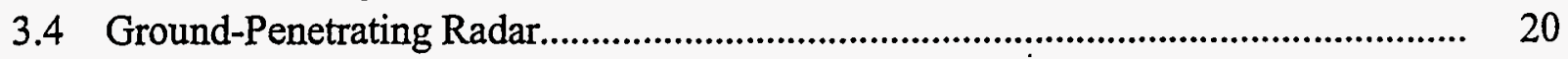

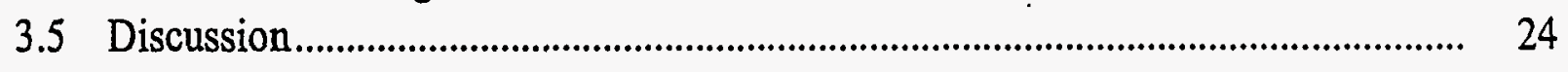

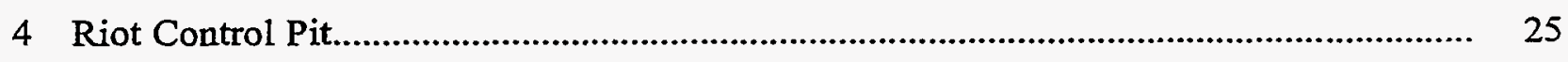

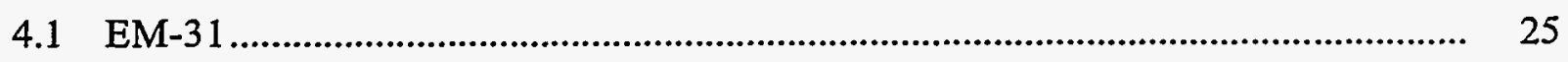

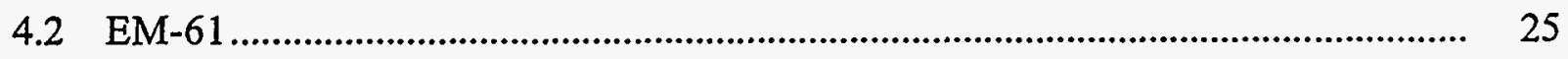

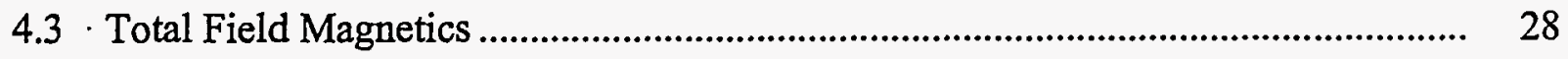

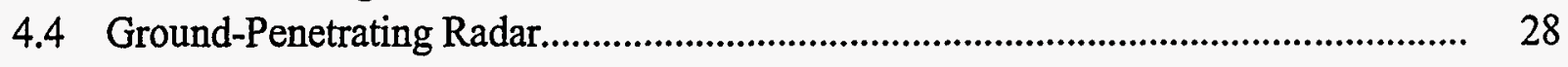

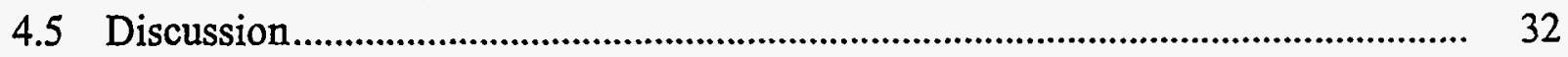

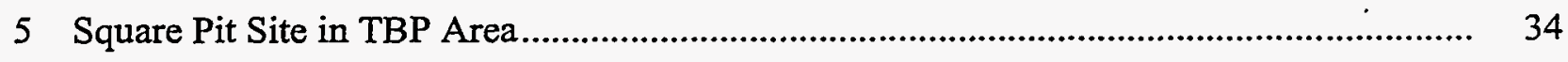

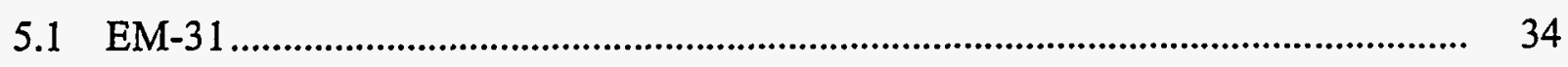

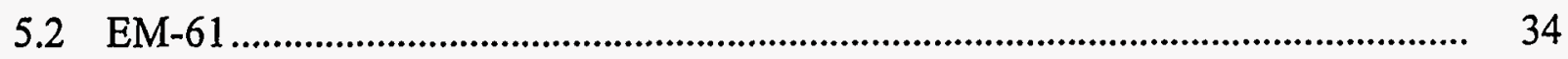

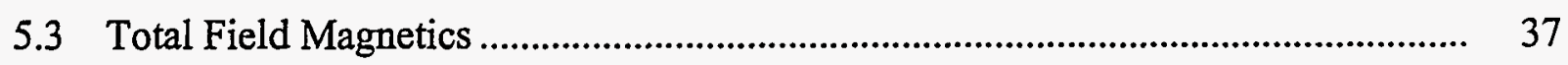

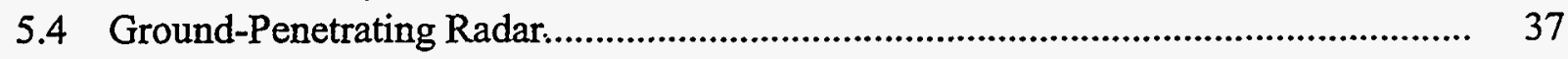

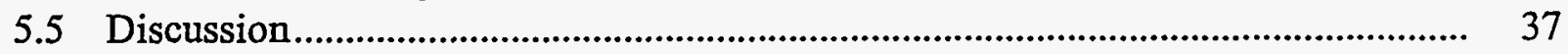




\section{Contents (Cont.)}

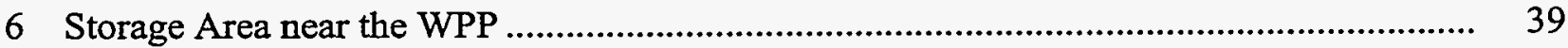

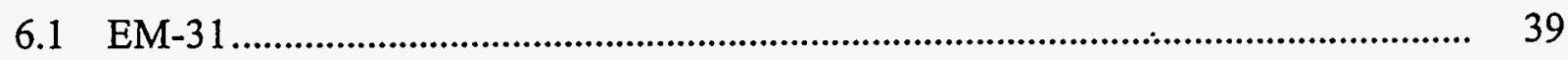

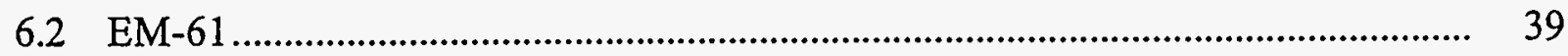

6.3 Total Field Magnetics ................................................................................ 42

6.4 Ground-Penetrating Radar........................................................................ 42

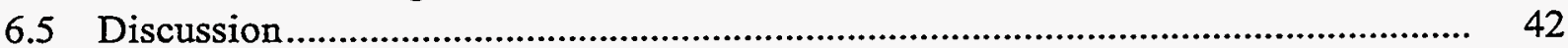

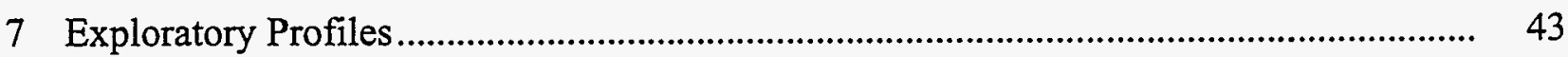

7.1 Suspected Trench near South Beach Trench Site ................................................ 43

7.2 Suspected Filled Trench at Ruin Site ........................................................ 48

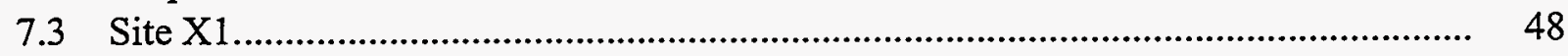

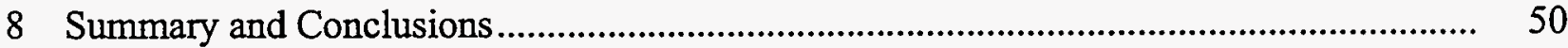

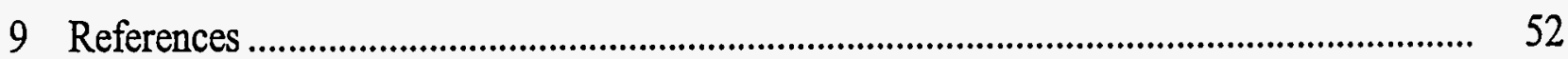

Appendix A： GPR Profile Line Coordinates and Settings .............................................. 55

Figures

1 Location of J-Field in the Edgewood Area at APG....................................................

2 Location of Geophysical Survey Grids and Site Features, J-Field ............................... 3

3 EM-31 Electromagnetics Maps at Mustard Pit A: Profiles Parallel to $\mathrm{X}$-Axis, B: Profiles Parallel to Y-Axis.................................................................. 10

4 EM-61 Electromagnetics Map, Mustard Pit ................................................... 11

5 Total Field Magnetics Map, Mustard Pit............................................................ 13

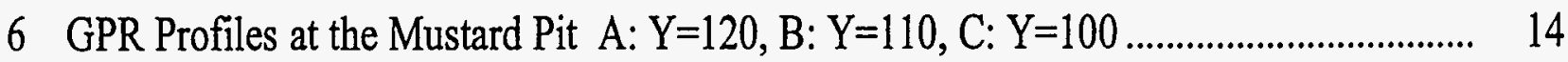

7 GPR Profiles along $\mathrm{X}=160$ at the Mustard Pit A: Interpreted Data, B: Uninterpreted Data..

8 EM-31 Electromagnetics Maps, VX Pit A: Profiles Parallel to X-Axis, $\mathrm{B}$ : Profiles Parallel to Y-Axis . 
Figures (Cont.)

$9 \quad$ EM-61 Electromagnetics Map, VX Pit......................................................................... 19

10 Total Field Magnetics Map, VX Pit ........................................................................... 21

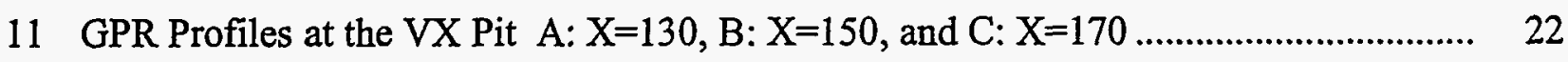

12 GPR Profiles along $\mathrm{Y}=120$ at the VX Pit A: Interpreted Data, B: Uninterpreted Data.

13 EM-31 Electromagnetics Map, Riot Control Pit A: Profiles Parallel to Y-Axis, B: Profiles Parallel to X-Axis

14 EM-61 Electromagnetics Map, Riot Control Pit ............................................................. 27

15 Total Field Magnetics Map, Riot Control Pit................................................................... 29

16 GPR Profiles at the Riot Control Pit A: $X=100, B: X=150$, and C: $X=200 \ldots \ldots \ldots \ldots \ldots \ldots . .30$

17 GPR Profiles at the Riot Control Pit A: $X=240, B: X=260$, and C: $X=280 \ldots \ldots \ldots \ldots \ldots \ldots \ldots . .31$

18 GPR Profile along $\mathrm{Y}=130$ at the Riot Control Pit A: Interpreted Data, B: Uninterpreted Data.

19 EM-31 Electromagnetics Map, Square Pit Site A: Profiles Parallel to Y-Axis, B: Profiles Parallel to X-Axis

20 A: EM-61 Electromagnetics Map, Square Pit Site B: Total Field Magnetics Map, Square Pit Site

21 GPR Profile along $\mathrm{X}=100$ at the Square Pit Site

22 EM-31 Electromagnetics Map, White Phosphorus Pit Area A: Profiles Parallel to X-Axis, B: Profiles Parallel to Y-Axis.

23 A: EM-61 Electromagnetics Map, White Phosphorus Pit Area B: Total Field Magnetics Map, White Phosphorus Pit Area.

24 EM-31, EM-61, and Magnetics Data Collected Perpendicular to a Suspected Trench near the South Beach Trench Site

25 EM-31, EM-61, and Magnetics Data Collected Perpendicular to the Suspected Trench at the Ruin Site 


\section{Figures (Cont.)}

26 Exploratory Profiles Collected at X1 Site: EM-31, EM-61, and Magnetic Data - Profiles 1 and 2 from West to East

27 Exploratory Profiles Collected at X1 Site: EM-31, EM-61, and Magnetic Data - Profiles 3 and 4 from South to North 


\title{
Phase II Environmental Geophysics at J-Field, Aberdeen Proving Ground, Maryland
}

\author{
by \\ B.E. Davies, M.D. Thompson, C.R. Yuen, J.E. Stefanov, G.J. Kuecher, \\ M.A. Benson, C.A. Padar, and L.D. McGinnis
}

\begin{abstract}
Geophysical studies were conducted at eight sites on the tip of Gunpowder Neck (J-Field) in the Edgewood Area of Aberdeen Proving Ground, Maryland. The results of the studies were used to delineate the extent of three former burning pits and help determine the necessity of further investigation at five potential areas of concern (PAOCs). Intensive investigations were performed at the three former burning pits and two of the PAOCs by using electromagnetic (EM-31 and EM-61), total field magnetometry, and ground-penetrating radar geophysical techniques. The successful integration of the four data sets characterized the extent, the approximate depth and nature of fill material, and the location of metallic debris at the three former burning pits. At the two PAOC sites that were intensively investigated, no continuous areas of metallic debris, indicating organized burials, were present. Less extensive exploratory profiles conducted at three other PAOC sites indicated the presence of buried metal objects, but they were inconclusive in defining the nature and extent of buried materials.
\end{abstract}

\section{Introduction}

Phase II environmental geophysical studies were conducted by Argonne National Laboratory (ANL) in support of the J-Field Remedial Investigation in the southern portion of Gunpowder Neck in the Edgewood Area at Aberdeen Proving Ground (APG) (Figure 1). Previous geophysical investigations at J-Field were performed in 1993 (see Daudt et al. 1994). Chemical agents and munitions have been destroyed at J-Field by open burning and open detonation at least since World War II. Through a review of historic aerial photographs (with limited resolution) and subsequent site reconnaissance, ANL identified areas of activity that require further evaluation (Benioff et al. 1995). The Phase II geophysical study area includes five locations identified during the previous site investigations as former or potential disposal sites. Figure 2 shows the approximate locations of the five sites, labeled 1 through 5 . The sites include three former burning pits: the Mustard Pit, the Methylphosphonothioic Acid (VX) Pit, and the Riot Control Pit (\#1 through \#3, respectively, on Figure 2). The Mustard and VX pits are part of 


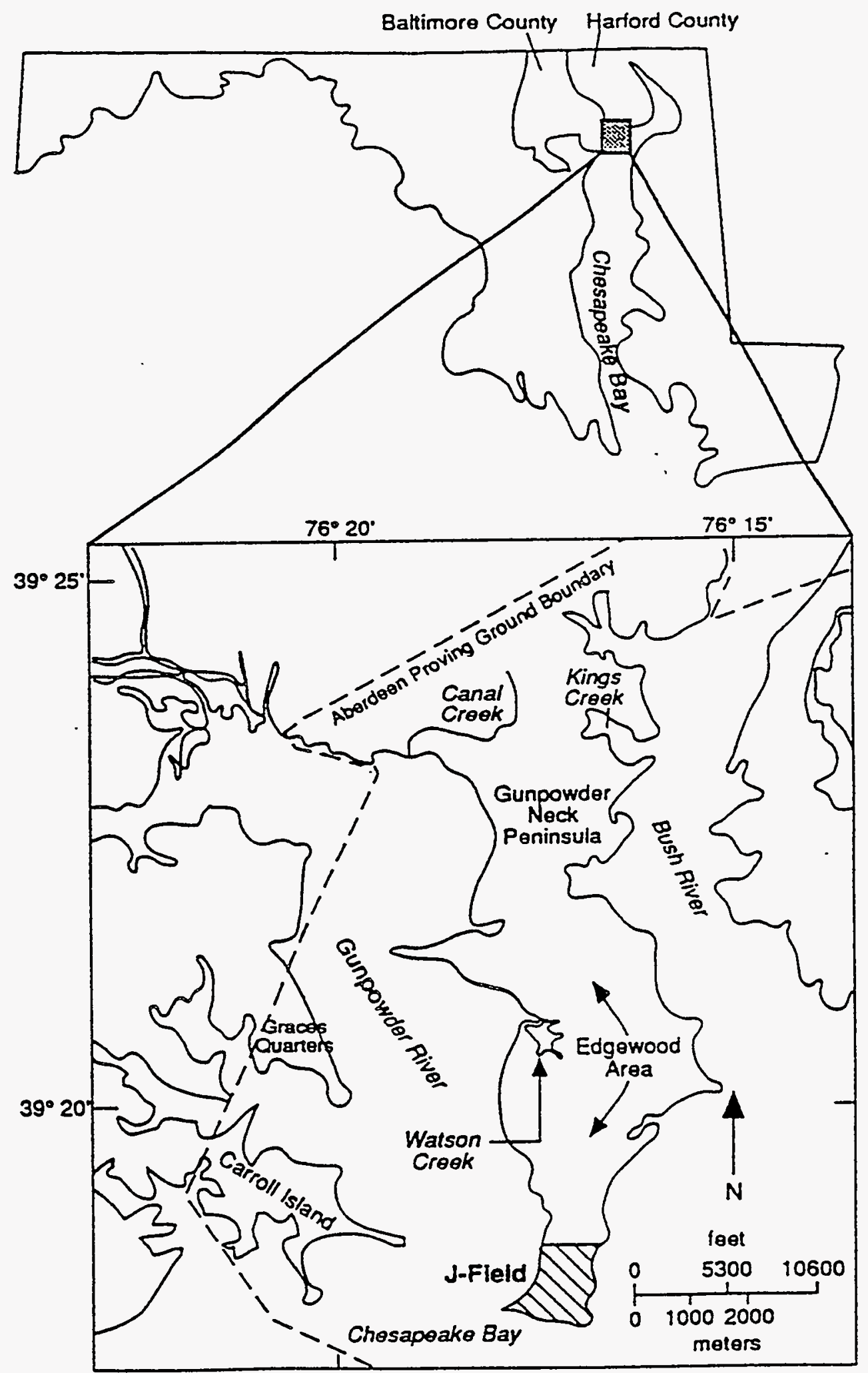

FIGURE 1 Location of J-Field in the Edgewood Area at APG 


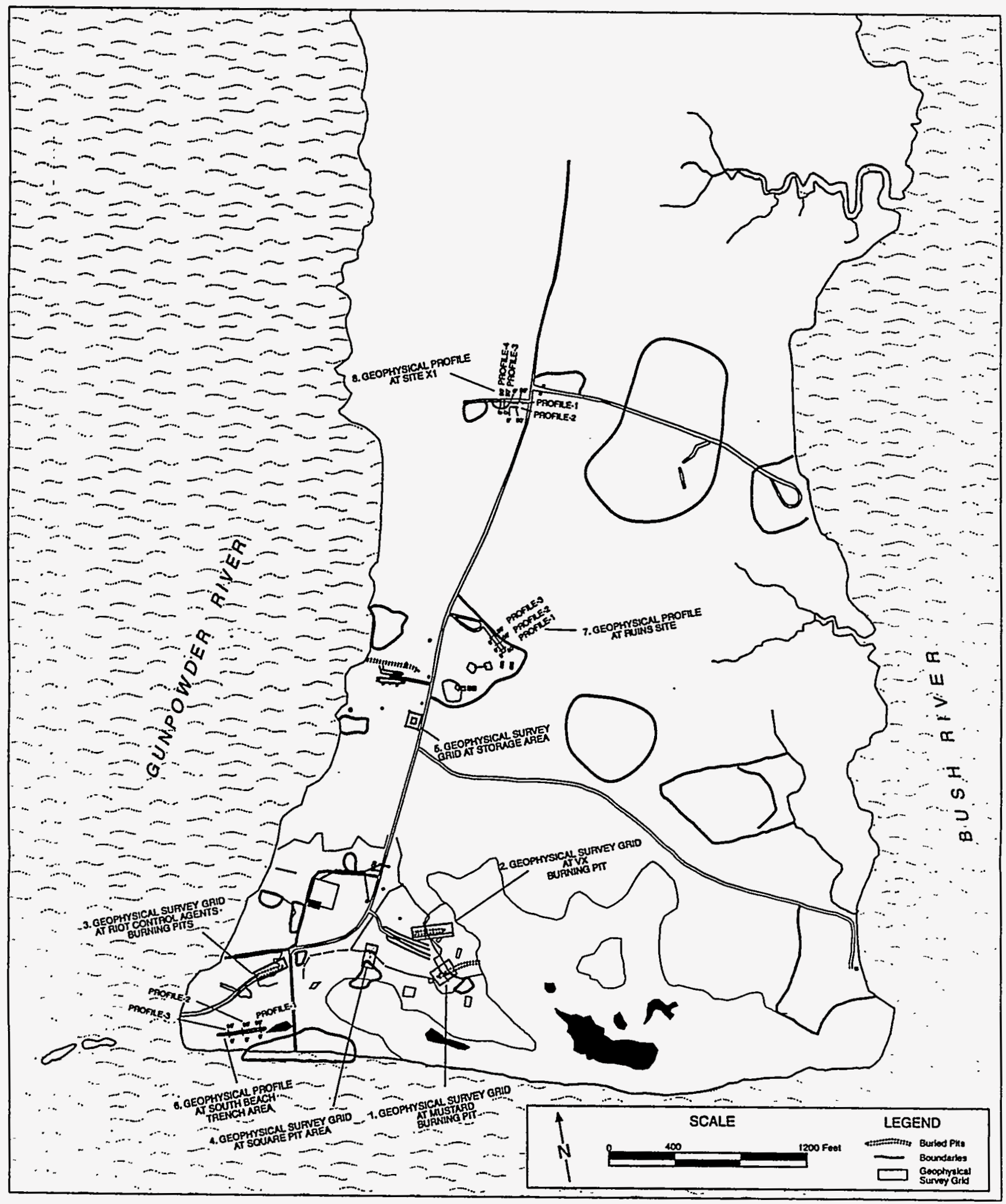

FIGURE 2 Location of Geophysical Survey Grids and Site Features, J-Field 
a group of five former burning pits collectively referred to as the Toxic Burn Pits (TBPs). Two other sites that were investigated also represent potential areas of concern (PAOCs): a suspected disposal area southwest of the TBPs (referred to as the Square Pit Site because of the presence of a partially buried metal box resembling a catch basin) (\#4 on Figure 2) and a suspected storage area associated with the White Phosphorus Pits (WPPs) (\#5 on Figure 2).

The objectives of the geophysical investigations (as outlined in the draft scope of work) are as follows:

- To delineate filled trenches and suspected waste disposal areas; and

- To characterize the extent of contamination near the suspected filled trenches, if possible.

Field activities were conducted in January 1995. Geophysical techniques used during this study included magnetics, electromagnetics, and ground-penetrating radar (GPR). In addition to the five sites listed above, exploratory profiles were conducted using each geophysical method at three other PAOCs. The three additional PAOC sites are suspect areas near the South Beach Trench south of the Riot Control Pit, a suspected filled trench at the Ruin Site, and two adjacent areas near Site X1. The approximate locations of these sites are indicated as \#6 through \#8 on Figure 2. The exploratory profiles were conducted to identify potential anomalous areas and determine whether additional, more concentrated investigation of these sites is necessary.

\subsection{Physiographic Setting and Site Survey}

J-Field lies within the Atlantic Coastal Plain physiographic province of Maryland. The study area is located in the southern end of Gunpowder Neck, a peninsula bounded by Gunpowder River to the west, Bush River to the east, and Chesapeake Bay to the south (Figure 1). The peninsula is a remnant of subareal erosion that occurred during a low sea level stand followed by a sea level rise and estuarine encroachment into the Gunpowder and Bush rivers. Both rivers are major tidal estuarine channels on the western shore of Chesapeake Bay. Elevations of J-Field range from about $12 \mathrm{ft}$ above mean sea level (msl) northwest of the Prototype Building to sea level at the shoreline. The majority of the areas studied are approximately 6 to $8 \mathrm{ft}$ above $\mathrm{msl}$.

The five surveyed sites cover approximately $70,000 \mathrm{ft}^{2}$ in the southern portion of J-Field. Because much of J-Field is wooded or marshland, each site required extensive vegetation clearing prior to surveying. Five separate 10 - to 20 -ft grid systems of wooden stakes and paint marks were used to guide the geophysical surveys (Figure 2). The grid coordinate systems were set up to cover the areas of interest; the locations within each system are referred to by the $\mathrm{x}$ and $\mathrm{y}$ coordinates $(\mathrm{x}, \mathrm{y})$. 


\subsection{Geology and Hydrogeology}

The stratigraphy of J-Field consists of Quaternary (Talbot Formation) sediments underlain by Cretaceous (Potomac Group) sediments. The Talbot Formation, consisting of interbedded sands, gravels, and silty clays, covers the entire J-Field area and varies in thickness from 110 to $160 \mathrm{ft}$ (Hughes 1993). On the basis of well log, gamma log, and offshore seismic data, Hughes $(1991,1993)$ identified three hydrogeologic units within the Talbot Formation at J-Field. The basal unit (Unit A) is a confined aquifer consisting of 13 to $50 \mathrm{ft}$ of gravelly sand and clay. Unit B, which overlies Unit A, is a leaky confining unit consisting of 36 to $107 \mathrm{ft}$ of silty, sandy clays containing organic matter. The contact between units $A$ and $B$ at J-Field dips eastward from approximately $60 \mathrm{ft}$ below $\mathrm{msl}$ in the west to $142 \mathrm{ft}$ below $\mathrm{msl}$ in the southeast. The uppermost unit of the Talbot Formation (Unit C) consists of 25 to $40 \mathrm{ft}$ of interbedded sands, silts, and clays that make up the unconfined, surficial aquifer (Hughes 1993). The Quaternary sediments are fluvial, estuarine, and marginal marine in origin (Southwick, Owens, and Edwards 1969).

The contact at the base of the Talbot Formation is an angular unconformity underlain by at least 300 to $400 \mathrm{ft}$ of Cretaceous sediments belonging to the Potomac Group. The Potomac Group units are continentally derived and represent several depositional systems: mostly fluvial, channel, and overbank or levee deposits. Cretaceous deposits in the area consist of interbedded clays and fine- to medium-grained quartz sands. These Cretaceous sediments likely belong to the Patapsco Formation of the Potomac Group. The unconformity between the Quaternary and Cretaceous sediments indicates an erosional contact during a lower sea level stand in the Pleistocene Epoch. The depth of erosion of the Cretaceous deposits indicates that a major stream channel, such as an ancestral Susquehanna River channel, was located beneath J-Field (Hughes 1993). Pleistocene erosional channels in Cretaceous sediments have been observed elsewhere within the Edgewood Area of APG (Oliveros and Vroblesky 1989; McGinnis et al. 1994a; Davies et al. 1995) and are common features of the Chesapeake Bay region (Kerhin et al. 1988; Colman et al. 1990).

The estimated elevation of the Precambrian crystalline basement underlying the Cretaceous sediments ranges from $350 \mathrm{ft}$ (Southwick, Owens, and Edwards 1969) to $800 \mathrm{ft}$ (Otton and Mandle 1984) below msl. Basement lithologies are similar to those found at the surface in the Piedmont province, which is located northwest of the fall line (Oliveros and Vroblesky 1989). The crystalline basement surface dips to the southeast at an angle of less than one degree (Bennett and Meyer 1952; Dingman et al. 1956; Southwick, Owens, and Edwards 1969). Previous geophysical studies at Beach Point and the Bush River Peninsula, located about $32,000 \mathrm{ft}$ to the north in the Edgewood Area of APG, revealed the Precambrian basement at a depth between 450 and $560 \mathrm{ft}$ beneath land surface (McGinnis et al. 1994b; Davies et al. 1995). In areas east of the fall line, including all of the areas discussed in this report, unconsolidated Atlantic Coastal Plain sediments overlie Piedmont basement rocks. 


\subsection{Instrumentation and Software}

Instruments used to collect geophysical data at the site included the following:

- Geonics EM-31 electromagnetic conductivity meter,

- Geonics EM-61 electromagnetic induction meter,

- EG\&G Geometrics Model G-822L cesium vapor magnetometer, and

- Geophysical Survey Systems, Inc. (GSSI), SIR-2 ground-penetrating radar.

The following paragraphs describe each of these instruments and the software used in data processing.

\section{Electromagnetic Conductivity Meter}

Electrical conductivity measurements were made with a Model EM-31, an electromagnetic instrument manufactured by Geonics Limited that provides a weighted mean value of conductivity, in millisiemens per meter $(\mathrm{mS} / \mathrm{m})$, for soils from just beneath the land surface to a depth of approximately $18 \mathrm{ft}$. Apparent conductivities measured by the EM-31 are weighted mean values measured over the entire depth range, with greater weights applied to shallower depths. Factors affecting subsurface conductivity include the following: moisture content of the soil, chemical composition of the groundwater, presence of nonaqueous-phase liquids, sand/silt/clay percentages, type of clay minerals, presence of metals, and presence of amphibolitic roadfill. The EM-31 data were interpreted in conjunction with the other geophysical and site topography data to help clarify and discriminate between factors affecting the measured apparent conductivity. Data were stored on an OMNI 720 data logger. Internal software permitted downloading directly into a laptop or desktop computer.

Apparent conductivities observed with the EM-31 at the eight sites ranged from -112 to $65 \mathrm{mS} / \mathrm{m}$. The background mean conductivity for the five main survey sites was about 15 to $20 \mathrm{mS} / \mathrm{m}$. The greatest conductivity ranges were observed near large surficial objects, buried underground cables, and buried wastes associated with the burning pits. Although metals are good conductors, their shape and orientation in relation to the azimuth of the EM-31 transmitter and receiver can result in an electromagnetic field in which the apparent conductivity, as read by the EM-31, is negative. Negative conductivities are an artifact of crossing high-conductivity gradients with the EM- 31 boom. When crossed at right angles by the EM-31, an elongated piece of metal (such as a buried pipe or wire) will produce a three-banded anomaly lineament. The lineament will consist of a central minimum bounded by two maxima (Geonics Limited 1992). This EM-31 signature for buried pipes has previously been observed at Beach Point and Kings Creek in APG (McGinnis et al. 1994b; Davies et al. 1995). 


\section{Electromagnetic Induction Meter}

The Geonics Limited Model EM-61, a portable, time domain, electrical induction instrument that transmits an electrical pulse into the ground, was used to measure secondary electromagnetic fields (in millivolts [mV]) caused by metallic objects ranging in depth from the surface to approximately $10 \mathrm{ft}$ beneath the instrument. Data are recorded on three channels (including a response from the upper coil, the lower coil, and the coil difference) and stored on an OMNI 720 data logger. The coil arrangement allows the EM-61 to discriminate between nearsurface objects and those at greater depths; the instrument is relatively insensitive to surface interference and more sensitive to buried metallic objects. Data were collected at a rate of three readings per second, resulting in a millivolt measurement approximately every foot along the profile.

Reduction of the electromagnetic and total field magnetic data was completed using digital audio tape (DAT) 31 and DAT 61 software provided by Geonics. The United States Geological Survey (USGS) minimum curvature gridding program, MINC (Cordell et al. 1992), was used to plot the data on a grid. Color-contour maps presenting the electromagnetic and total field magnetic data were produced by using COLORMAP software developed by ANL (Thompson 1994).

\section{Magnetometer}

Total field magnetic data were acquired by using the Model G-822L cesium vapor magnetometer manufactured by EG\&G Geometrics. The magnetometer is a continuous-recording (10 readings per second), total-field, microprocessor-based instrument capable of resolution of anomalies to one nanotesla $(1 \mathrm{nT})$.

Errors introduced into the magnetic data due to uncorrected diurnal variations and insufficient response speed to changing signals during the magnetic surveys were small compared with the amplitudes of the anomalies detected. Therefore, the anomalies displayed on the magnetics maps are qualitatively significant. Relatively small (10 to $100 \mathrm{nT})$ diurnal variations in the earth's magnetic field are caused largely by the interaction of fluctuating solar radiation and the ionosphere. Larger changes occur during solar storm events. In addition to diumal fluctuations, some error can be introduced through inadvertent changes in instrument position or attitude relative to the ground surface. Moving around obstacles or changing walking pace may also produce some positioning error. The study areas were cleared of most obstacles prior to the surveys to minimize these errors. Marks were placed on the data at $20-\mathrm{ft}$ intervals and at the beginning and end of each survey line. Digital and graphic data readouts are included with the data logging computer. If significant errors were noted while conducting the survey, the profile was redone. Careful control of data acquisition and processing procedures kept errors to a minimum. Spacial corrections were applied to the magnetic data by using DAT 31 software developed by Geonics for the EM-31. 


\section{GPR}

GPR surveying was accomplished by using a GSSI Model SIR-2. Data from the SIR-2 system were downloaded directly to a personal computer. Continuous profiling was performed using a 100-megahertz (MHz) monostatic antenna. Radan III computer software written by GSSI was used to process the GPR data. A thermal printer was used to examine the GPR profiles in the field.

Reflector characteristics, such as changes in amplitude, discontinuities between reflectors, truncation of reflectors, and changes in reflector slope, are used to identify and delimit features observed during the GPR surveys. For example, small metallic items appear as sharp hyperbolas in the GPR data. Changes in the amplitude of reflectors represent changes in the electrical properties in the subsurface. Depth estimates made in this report are based on velocities given by the manufacturer (GSSI 1987). GSSI estimates the two-way travel time for "average" soil at between 7 and 9 nanoseconds per foot (ns/ft). 


\section{Mustard Pit}

The former Mustard Pit is located approximately $300 \mathrm{ft}$ southeast of the main TBPs (Figure 2). The pit is currently filled and has no surface expression. The original survey grid for the Mustard Pit measured $100 \mathrm{ft} \times 80 \mathrm{ft}$ in area. Based upon the preliminary survey results, the grid was expanded to an area of $100 \mathrm{ft} \times 140 \mathrm{ft}$ (Figure 2). For the Mustard Pit survey grid, the $\mathrm{x}$-axis was oriented approximately $155^{\circ}$ east of north. Four monitor wells (JF71, JF72, JF73, and JF173) are located within the survey area. A gravel roadway is also present. These features are outlined on the figures presenting the geophysical data.

\section{$2.1 \quad E M-31$}

EM-31 conductivity measurements were collected with profiles spaced $5 \mathrm{ft}$ apart parallel to the $\mathrm{x}$-axis and with profiles spaced 10-ft apart parallel to the $\mathrm{y}$-axis in the Mustard Pit area. Figures $3 \mathrm{~A}$ and $3 \mathrm{~B}$ present separate maps of the EM-31 data collected in each direction. Apparent conductivities at the Mustard Pit ranged between -3 and $65 \mathrm{mS} / \mathrm{m}$.

In general, conductivities decrease toward the south and southwest (lower right in Figure 3). The conductivity high in the area between approximately $x=100-120$ is probably associated with pushout material from the main TBPs. In Figure 3A, the Mustard Pit is centered along the $x=160$ coordinate between approximately $y=90-145$. The pit is indicated by a conductivity low bounded by conductivity highs on either side. In Figure 3B, the Mustard Pit is seen as two conductivity lows along the $\mathrm{x}=160$ profile. A larger anomaly is present between $y=125-150$, with a smaller-magnitude anomaly centered at approximately $y=100$.

Other features associated with the Mustard Pit area include conductivity highs at $(195,135)$ and $(120,40)$ caused by storage drums and monitor wells. An unexplained highconductivity feature, centered at $(190,70)$ within an area of amphibolite road fill (Figure 3A), is not associated with any surface feature. The feature was not found in the y-direction profiles (Figure 3B), probably because a profile was not run along $x=190$ because of obstructions to the EM-31 instrument. Small anomalies were detected with the magnetometer and the EM-61 at this location.

\section{$2.2 \quad E M-61$}

Figure 4 presents a color-contour plot of the lower-coil EM-61 survey data. The survey shows a positive-millivolt trend indicating buried metals along the $\mathrm{x}=160$ profile, between $y=65-150$; this is interpreted as the Mustard Pit location. The part of the pit between $y=125-150$ contains the greatest number of buried metallic objects. A small area centered at $(160,70)$ also shows an EM-61 response indicative of additional buried metals, although metallic anomalies are present throughout the area believed to be the former Mustard Pit. 


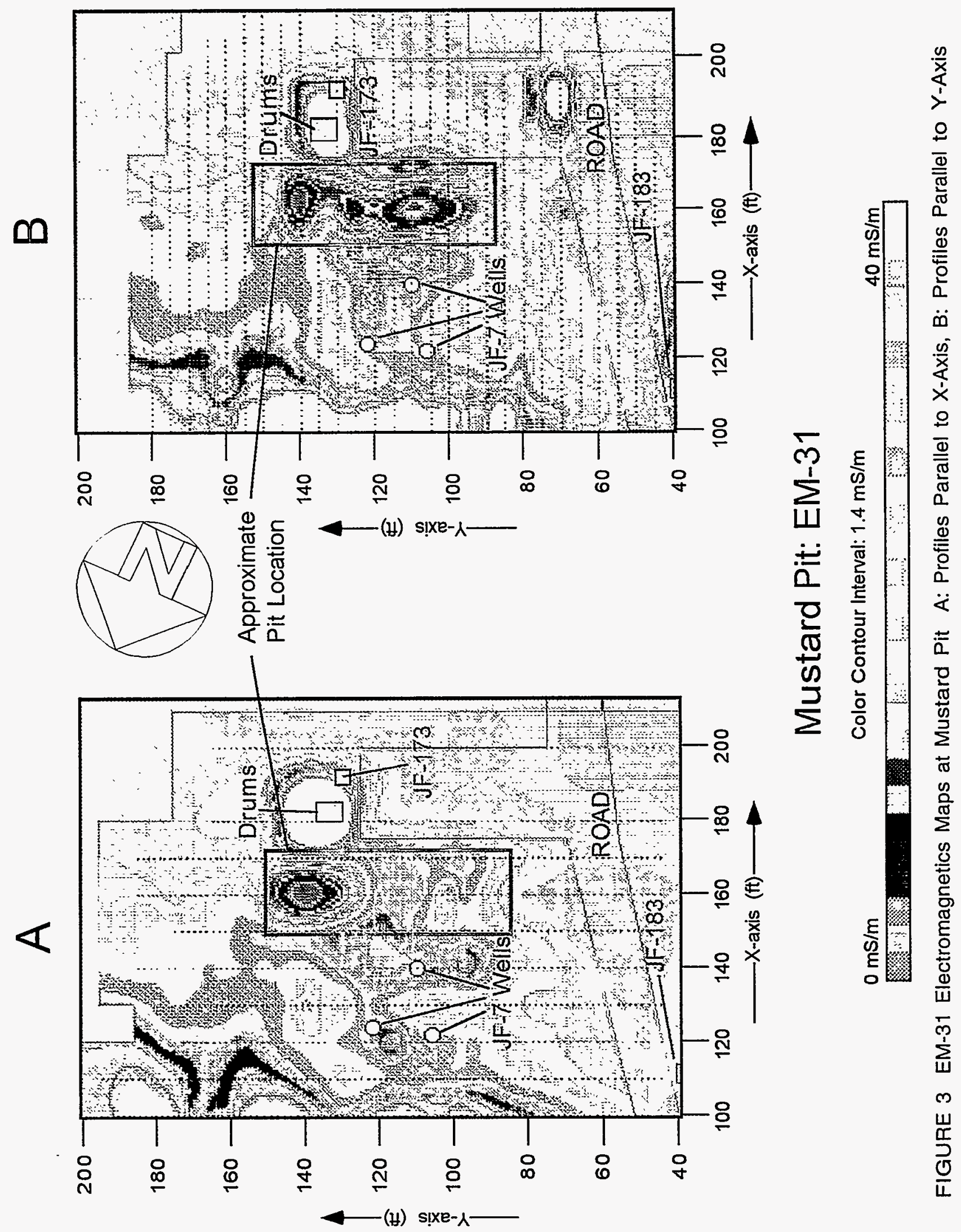




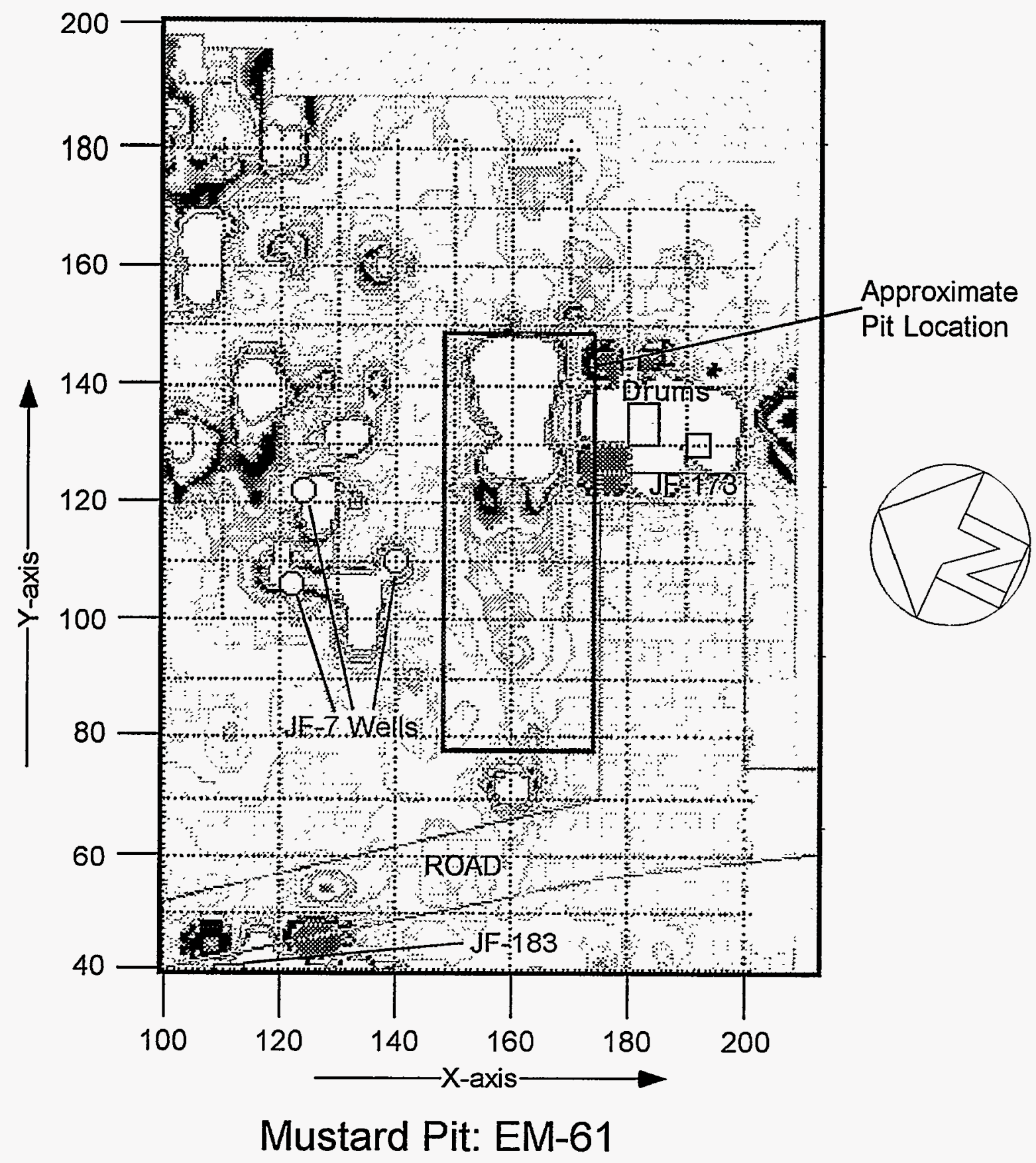

$-280 \mathrm{mV} \quad$ Color Contour Interval: $20 \mathrm{mV} \quad 290 \mathrm{mV}$

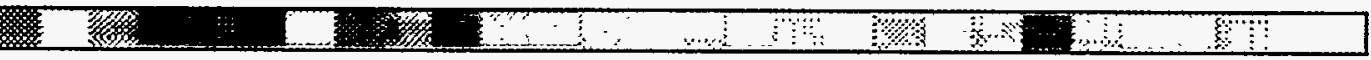

FIGURE 4 EM-61 Electromagnetics Map (Lower Coil), Mustard Pit 
A review of Figure 4 also shows that scattered electromagnetic anomalies with unknown sources are present throughout the survey area between $x=100-140$ and $y=100-180$. As with the conductivity data, these anomalies are believed to be associated with pushout from the main TBP activities. Larger anomalies caused by the monitor wells and staged drums were also recorded.

\subsection{Total Field Magnetics}

The total field magnetics data for the Mustard Pit area are presented in Figure 5 and generally correspond with data collected during the EM-61 survey. The magnetic expression of the Mustard Pit appears as a series of alternating polarity anomalies located generally between $x=150-170$ and $y=60-150$. Magnetic anomalies associated with the site monitor wells and staged drums discussed previously are also present. Small and large magnetic anomalies caused by unknown, buried sources were observed throughout the survey area.

\subsection{Ground-Penetrating Radar}

A total of 37 GPR profiles were collected in the Mustard Pit area. The locations and GPR specifications of the profiles are listed in Appendix A. Four GPR profiles, three perpendicular to and one along the long axis of the pit, are examined in this section.

Figure 6 shows portions of three profiles (with interpretations) that cross the long axis of the Mustard Pit along the $y=100,110$, and 120 transects. The Mustard Pit is characterized by higher-amplitude reflectors within the trench; the horizontal limits are defined by truncated dipping reflectors. The interpreted bottom of the pit is speculative; the higher-amplitude reflectors may represent either material within the pit or the base of the trench. As interpreted, the bottom of the pit is at approximately $50 \mathrm{~ns}$, which is roughly equivalent to 4 to $6 \mathrm{ft}$ in depth.

Figure 7A shows an interpreted GPR profile along the pit's axis $(x=160)$. In the uninterpreted profile shown in Figure 7B, the reflectors interpreted as the Mustard Pit are more apparent. The western terminus of the pit (approximately $y=70$ ) is marked by eastward-dipping reflectors, and by a disturbed region consisting of discontinuous reflectors $(y=70-80)$. The reflectors designated as the base of the pit in Figure 7 again may represent either the pit bottom or reflective material within the pit. The base of the pit appears to become slightly more shallow further along the y-axis until the "picked" reflector sequence becomes truncated by a region of discontinuous reflectors from $y=125-140$. An object buried at a depth of approximately 4 to $5 \mathrm{ft}$ is indicated in Figure 7 at $(160,150)$. This location corresponds to strong millivolt highs, magnetic anomalies, and apparent conductivity lows (Figures 3, 4, and 5). A shallower buried object at $(160,60)$ corresponds to the location of a magnetic anomaly. 

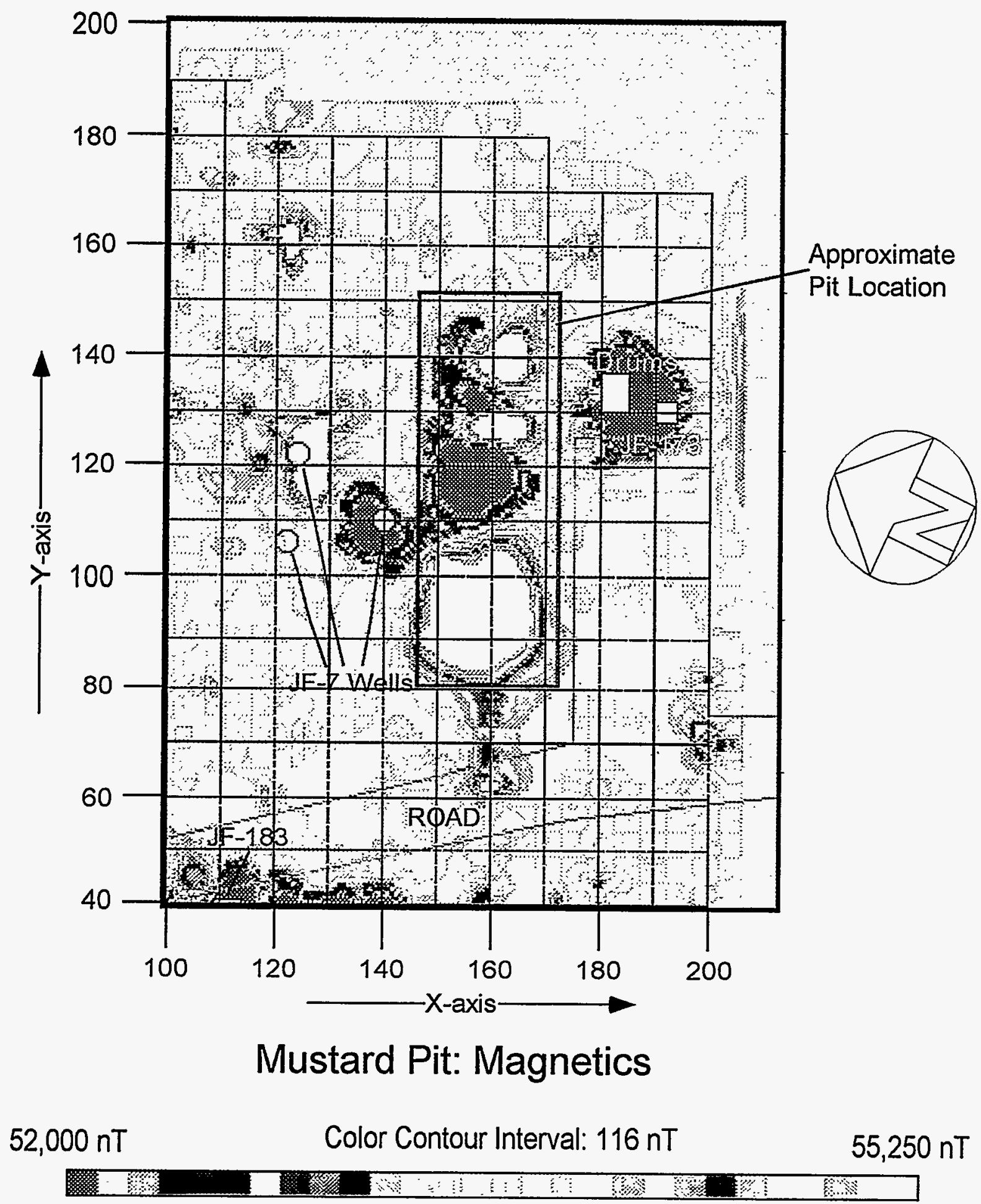

FIGURE 5 Total Field Magnetics Map, Mustard Pit 


\section{Mustard Pit: GPR}
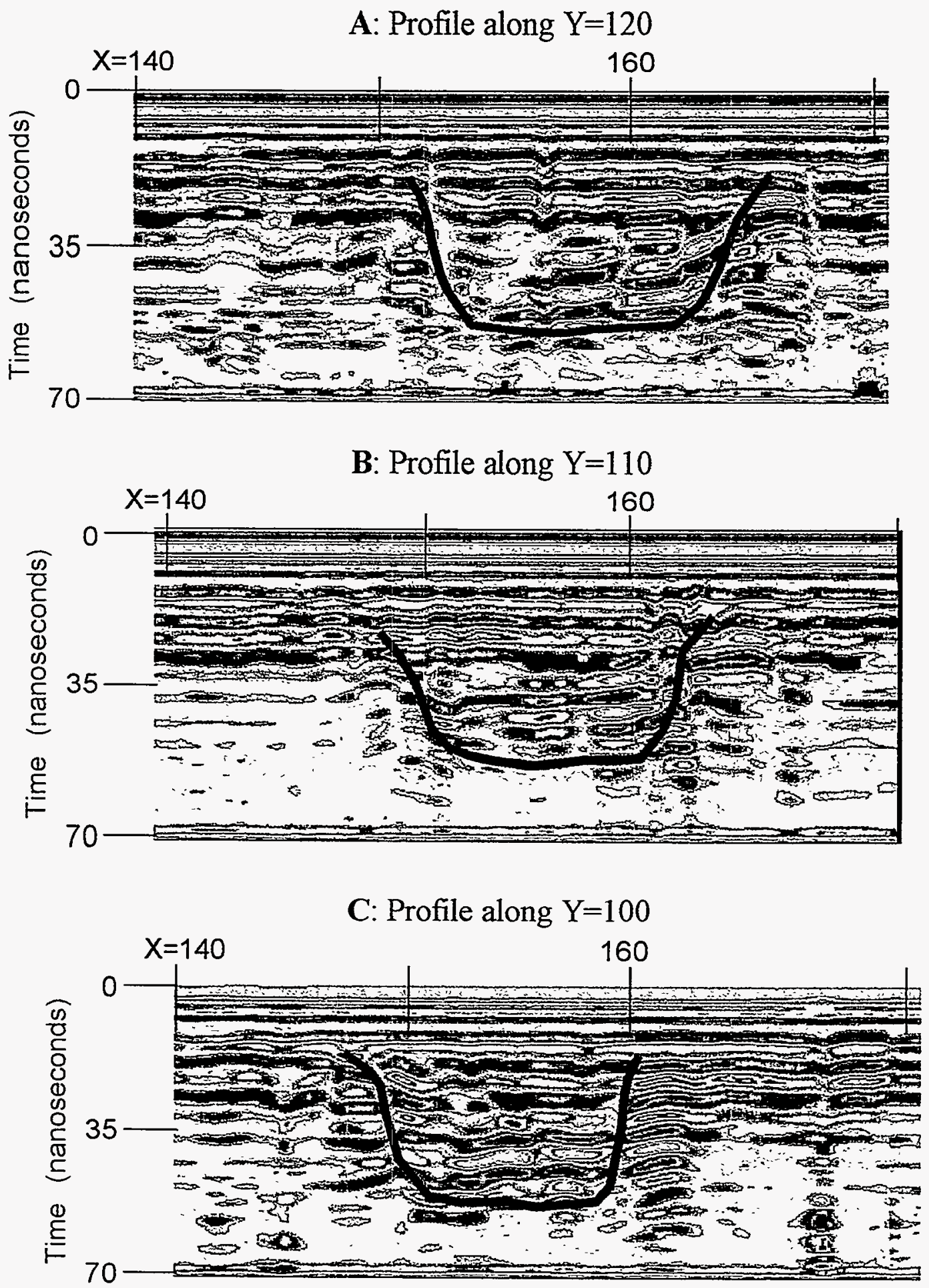

FIGURE 6 GPR Profiles at the Mustard Pit A: $Y=120, B: Y=110, C: Y=100$ 


\section{Mustard Pit GPR}
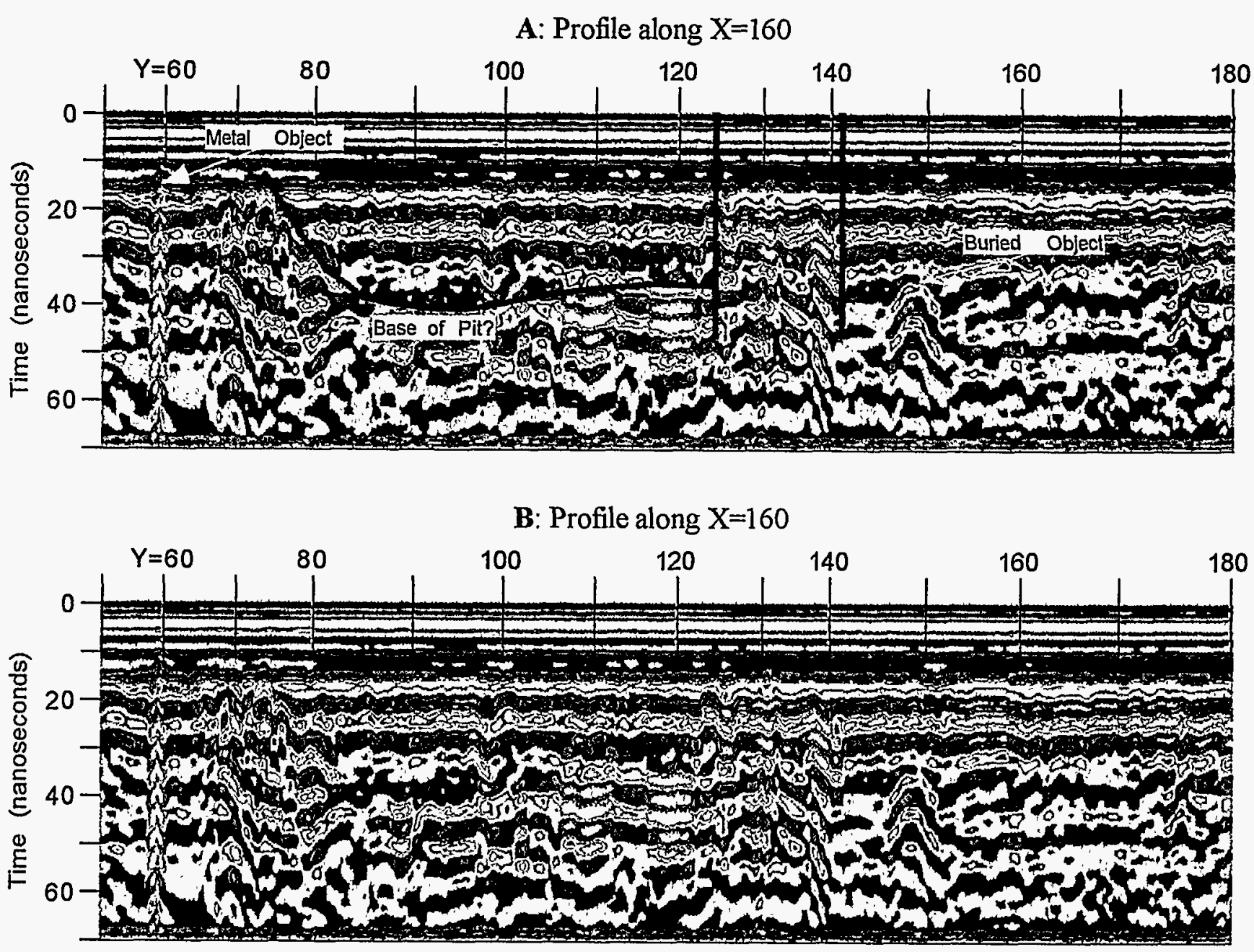

FIGURE 7 GPR Profiles along $X=160$ at the Mustard Pit A: Interpreted Data, B: Uninterpreted Data 


\subsection{Discussion}

The geophysical signature of the Mustard Pit is characterized by apparent lowconductivity anomalies, magnetic bipolar anomalies, positive millivolt anomalies, and higheramplitude GPR reflectors. The conductivity low is shouldered on both its north and south sides by linear conductivity highs. The relationship between a central low and shouldering high conductivities is similar to that for a buried pipe and indicates that buried conductive material must be present at this location. The conductivity low is an artifact caused by crossing a large conductivity gradient with the EM-31 boom and actually represents an area of high conductivity. The conductivity data, millivolt data, and GPR profiles indicate that the region of the pit from $y=110-150$ should be examined further because buried metals are present.

Conductivities decrease toward the east, south, and southwest of the survey grid (Figure 3). The topography of the study area generally decreases toward the east; the $x=100$, $y=100$ comer of the survey grid is the topographic high. In general, the water table is closer to the surface in areas of lower elevation. A thinner unsaturated zone will normally result in higher subsurface conductivities. More conductive soils and/or groundwater are present in the northern portion of the survey area, described earlier as pushout materials from the TBPs. The lower conductivities to the east, south, and southwest indicate an area less disturbed by anthropogenic activities. 


\section{VX Pit}

The former VX Pit is located approximately $50 \mathrm{ft}$ northeast of the main TBPs (Figure 2). The pit is currently filled and has no surface expression. The survey grid for this area measures approximately $250 \mathrm{ft} \times 80 \mathrm{ft}$. The grid system is situated nearly along the true north and east directions. The southwest corner of the survey grid $(100,80)$ is the northeast berm of the northernmost main burning pit. Four monitor wells (P-3, JF61, JF62, and JF63) are located within the survey area. Two soil borings (VXBOR1 and VXBOR2) are also within the survey grid. A gravel roadway crosses the western end of the grid. These features are shown on the VX Pit data figures.

\section{$3.1 \quad E M-31$}

EM-31 conductivity measurements were collected along east/west and north/south profiles spaced $10 \mathrm{ft}$ apart in the VX Pit area. Apparent subsurface conductivities ranged between -112 and $52 \mathrm{mS} / \mathrm{m}$, which is the largest range of the five sites. The large negative apparent conductivities result from crossing buried metal objects, which creates large conductivity gradients, as described in Section 1.3.

Figures $8 \mathrm{~A}$ and $8 \mathrm{~B}$ show the color-contoured EM-31 data collected parallel to the $\mathrm{x}$-axis and the $y$-axis, respectively. In general, conductivities increase toward the east and southeast. The conductivity highs correspond to low-lying terrain that contained ponded water at the time of the survey. Low conductivity artifacts, associated with positive magnetic and EM-61 anomalies, are scattered throughout the VX Pit survey area. The VX Pit is believed to be associated with the east/west-trending, low-conductivity feature approximately along the $y=120$ coordinate between $x=120-200$. The presence of the VX Pit at this location is confirmed by soil boring VXBOR1 $(178,124)$, which contained residual fuel used during burning activities. The eastern portion of this anomaly (between approximately $\mathrm{x}=180-200$ ) may be a true conductivity low caused by the residual fuel, although smaller amounts of buried metals are present in this area and may cause the low apparent conductivity. The low conductivity anomaly north of the VX Pit, centered at $(155,145)$, is the largest-amplitude minimum and represents an artifact associated with both visible and buried metallic objects. To distinguish between true conductivity lows and artifacts caused by high gradients, it is necessary to first compare the EM-31 data with the magnetometer and EM-61 data sets.

\section{$3.2 \quad E M-61$}

Figure 9 presents a color-contour plot of the lower-coil millivolt survey data for the VX Pit. Profiles were collected at 10-ft intervals in the north/south direction and at 20 - $\mathrm{ft}$ intervals east to west. Strong positive electromagnetic field responses were recorded at the VX Pit and the 

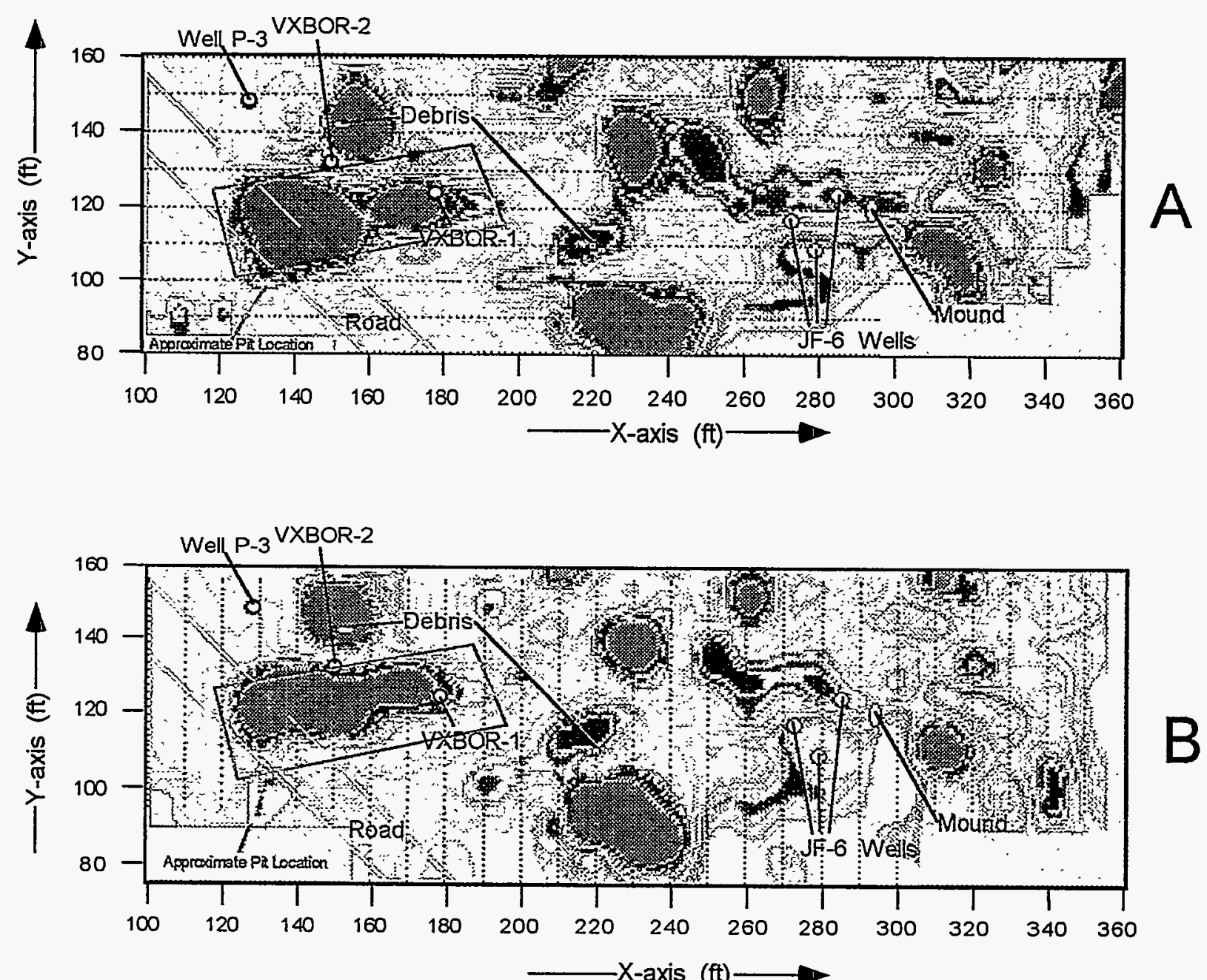

\section{VX Pit: EM-31}

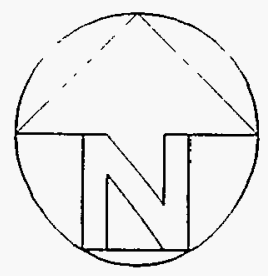

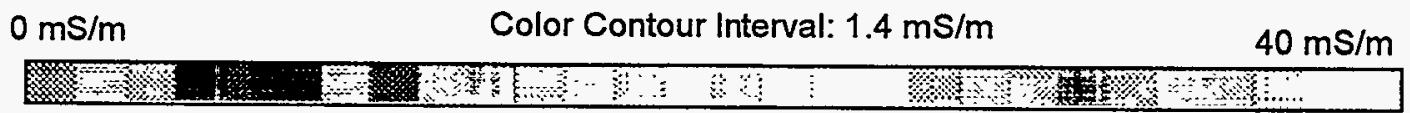

FIGURE 8 EM-31 Electromagnetics Maps, VX Pit A: Profiles Parallel to X-Axis, B: Profiles Parallel to $Y$-Axis 

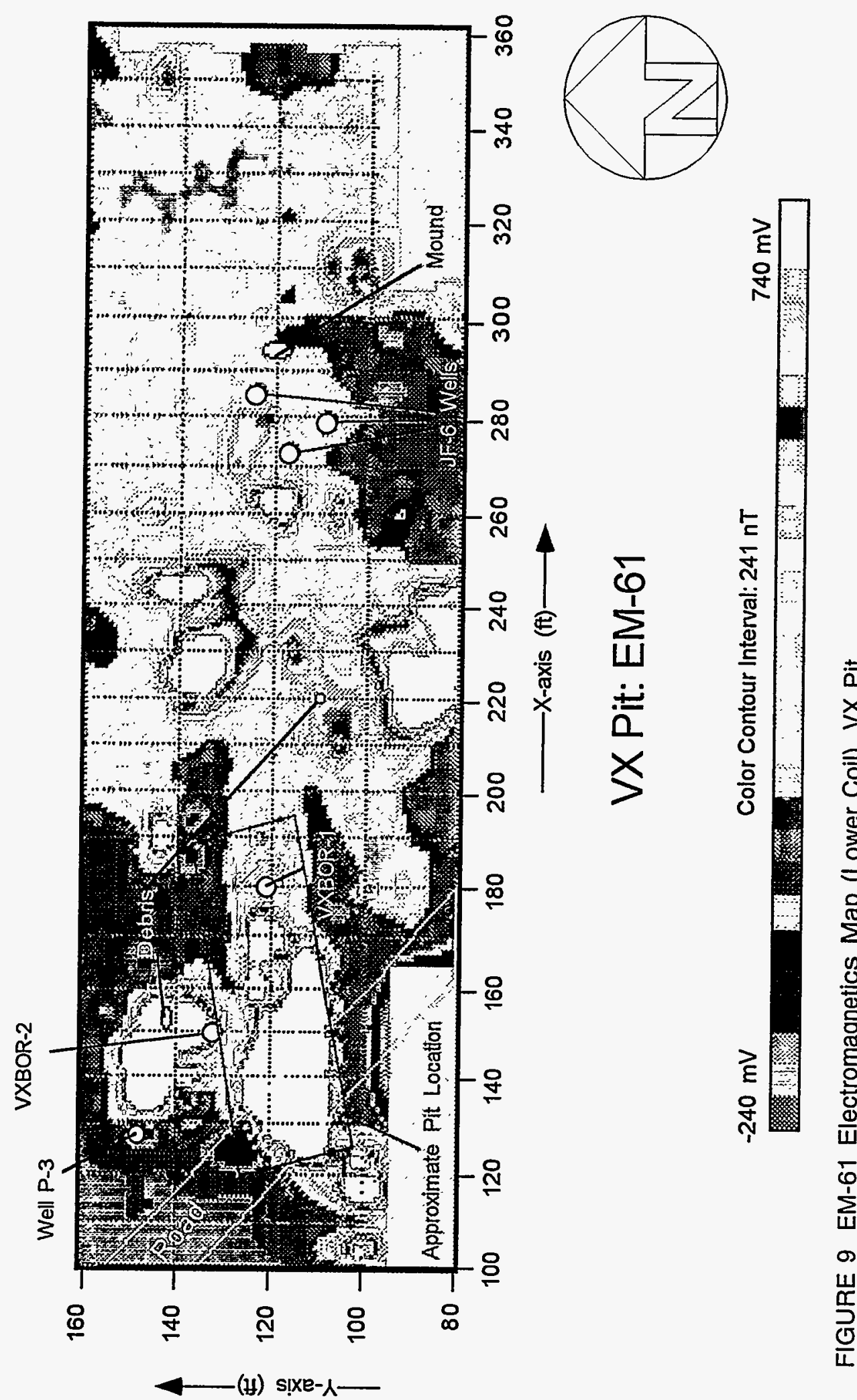

$\sum_{i}^{1}$

o
㟧
$\frac{0}{0}$ 
location of other conductivity lows, indicating the presence of substantial amounts of buried metallic debris. The largest anomalies, observed in the areas immediately north and east of the VX Pit, likely represent pushout material from activities at the pit.

\subsection{Total Field Magnetics}

Figure 10 presents the color-contoured, total-field magnetic data obtained for the VX Pit survey area. The magnetic data were collected along north/south profiles spaced at 5 -ft intervals. The eastern two-thirds of the survey area is dominated by scattered, randomly located magnetic anomalies. Some of these can be attributed to the three monitor wells and the small earthen mound shown in Figure 10. The majority of the magnetic anomalies in the eastern part of the survey area do not correlate to surface features and must be caused by subsurface sources. Most of these anomalies are interpreted to be pushout material associated with activities at the VX Pit.

The signature of the VX Pit dominates the western third of the survey grid and is marked by a positive/negative anomaly pair that trends from $x=120-190$ approximately along $y=120$. The magnetic low is offset to the north of the corresponding magnetic high, which is the usual case for bipolar magnetic signatures in the northern hemisphere. The spatial position for the VX Pit, as indicated by the magnetic data, correlates well with the conductivity results. Two other magnetic anomalies were observed in the western third of the survey area. The first, centered at $(125,150)$, is associated with monitor well P-3. The second, centered at $(155,145)$, is attributed to metallic debris observed at the ground surface.

\subsection{Ground-Penetrating Radar}

A total of 37 GPR profiles were collected in the VX Pit area. The locations and GPR specifications of the profiles are listed in Appendix A. Three north/south-oriented profiles (located along the $x=130,150$, and 170 profile lines) that cross the inferred position of the VX Pit are shown (with interpretation) in Figure 11. The VX Pit is expressed as a zone of strong reflections on the GPR sections, with discontinuous and hyperbolic reflectors within the zone. The signature of the VX Pit decreases in reflector amplitude toward the east - indicated by the contrast between the GPR profile along $x=170$ (bottom panel) and the profile along $x=150$ (middle panel).

An east/west GPR profile, recorded along grid coordinate $y=120$ between $x=100-280$, is shown (with interpretation) in Figure 12A. Figure 12B shows the profile without interpretation. The western third of the profile is coaxial with the VX Pit. A zone of high-amplitude, discontinuous, and hyperbolic reflectors is indicated in the coordinate range from $x=120-195$. These reflectors are believed to represent buried debris in the former burning pit. High-amplitude 


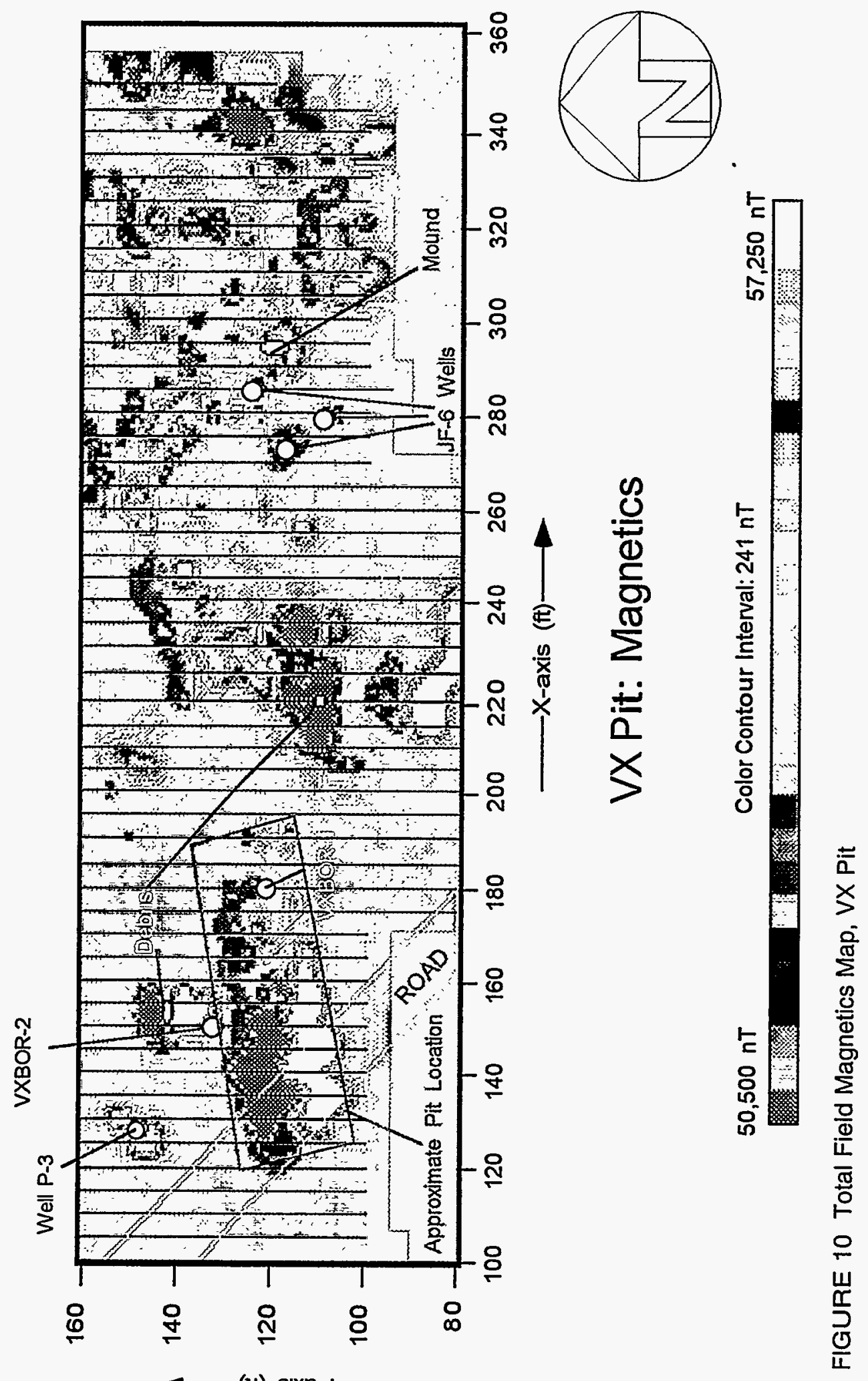




\section{VX Pit: GPR}

A: Profile along $X=130$
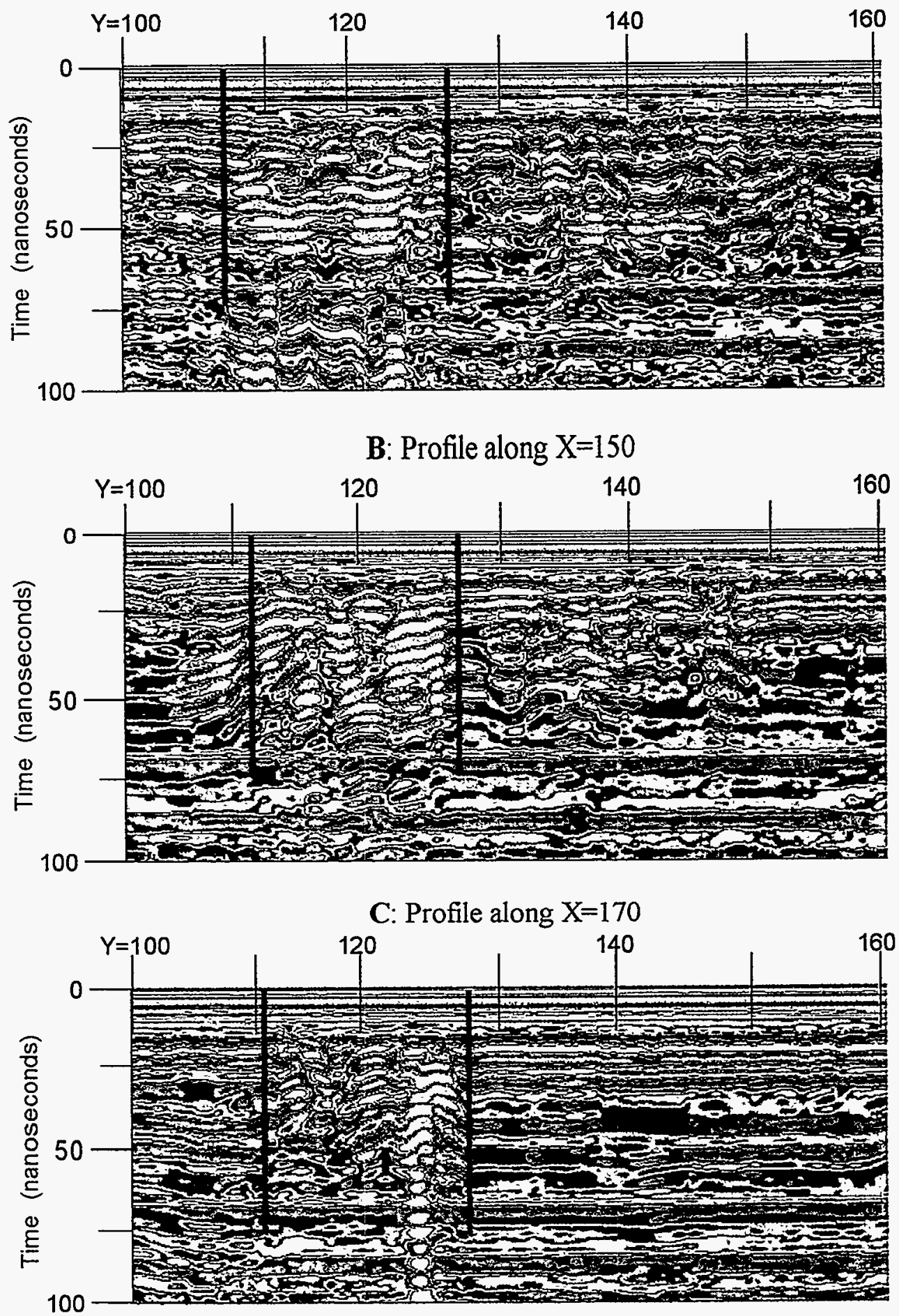

FIGURE 11 GPR Profiles at the VX Pit A: $X=130, B: X=150$, and C: $X=170$ 


\section{VX Pit: GPR}
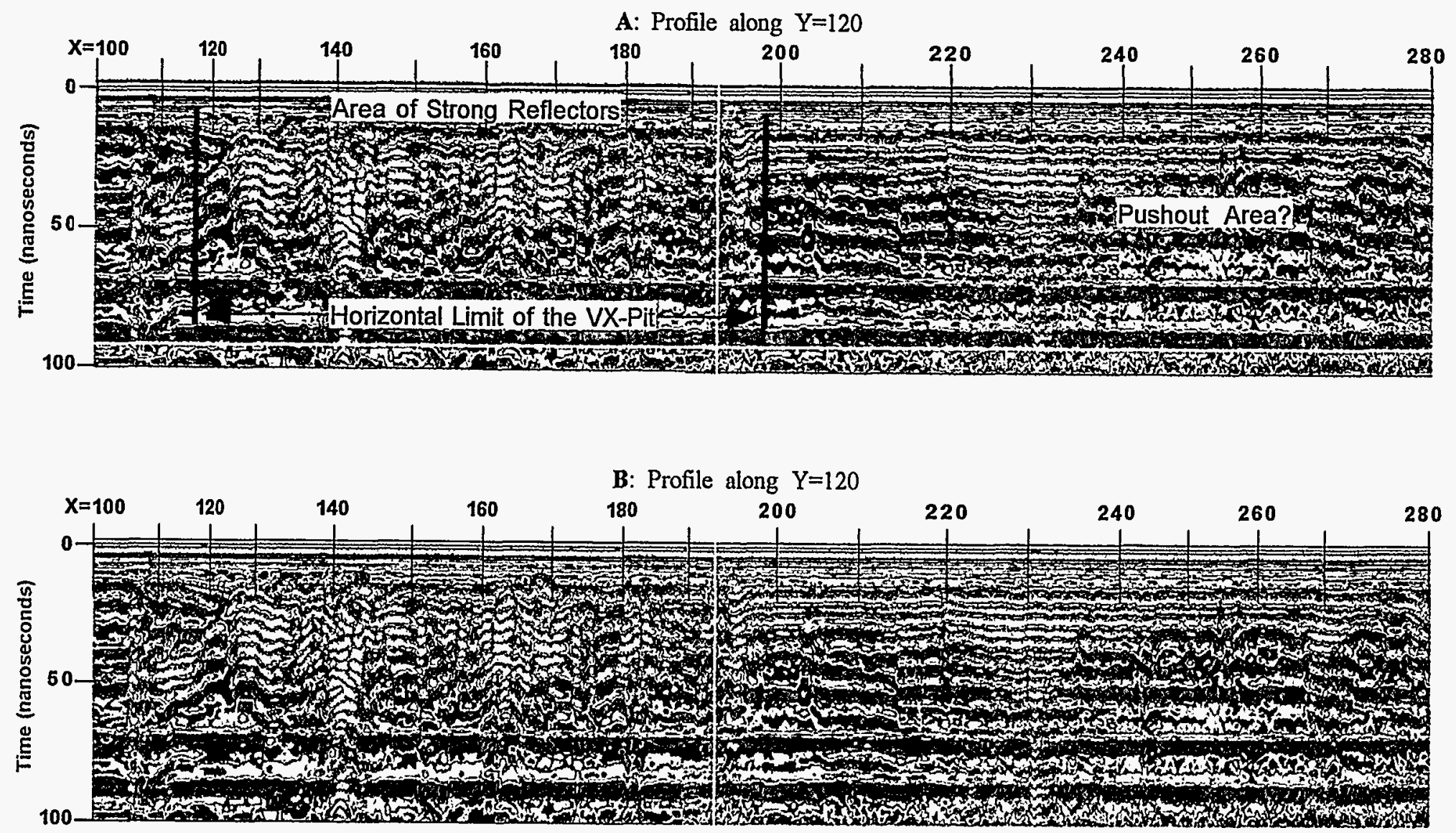

FIGURE 12 GPR Profiles along $Y=120$ at the VX Pit A: Interpreted Data, B: Uninterpreted Data 
reflectors were recorded west of the VX Pit, but become continuous over distances of 25 to $50 \mathrm{ft}$ within the VX Pit. The gravel road is indicated by a. shallow reflector between approximately $\mathrm{x}=115-132$.

\subsection{Discussion}

The signature of the VX Pit is characterized by negative conductivity values (which are artifacts), bipolar magnetic fields, large positive millivolt anomalies, and higher-amplitude GPR reflectors. The boundaries of the VX pit excavation are not as evident from the GPR data as at the Mustard Pit, probably because of metallic debris buried in the former VX Pit. The depth of the pit cannot be determined from the GPR data alone. The geophysical data indicate that the region of the pit from $x=120-175$ should be examined further because of the presence of buried material.

The conductivity data trend higher toward the east and southeast of the survey grid. This trend follows the site topography and is related to an inferred decrease in the depth to the water table and the presence of ponded water at the surface in these locations. Because of the large amounts of metallic debris at the site, ANL could not establish the presence of conductive or nonconductive groundwater plumes. An area of residual fuels may be outlined by a lowconductivity zone east of boring VXBOR1, which is inferred to be hydraulically downgradient of the VX Pit (Figure 8). 


\section{Riot Control Pit}

The former Riot Control Pit is in the southwestern part of J-Field (Figure 2). The ground surface over the pit is uneven; vegetation, including small trees, was removed prior to the survey. An area of phragmites prevented surveying in the western portion of the site. The survey grid measured approximately $200 \mathrm{ft} \times 60 \mathrm{ft}$ and was extended further toward the north along selected profiles where vegetation allowed. The $y$-axis of the Riot Control Pit grid was oriented approximately $17^{\circ}$ west of north (Figure 2). Three monitor wells (JF11, JF12, and JF13) are located outside the survey grid near the southwest corner $(100,100)$. No surficial metallic objects were observed at the RCP site.

\section{$4.1 \quad E M-31$}

EM-31 conductivity measurements were collected at the Riot Control Pit along profiles parallel to the $y$-axis spaced $5 \mathrm{ft}$ apart and along profiles parallel to the $\mathrm{x}$-axis spaced $10 \mathrm{ft}$ apart. Apparent subsurface conductivities ranged between -12 and $27 \mathrm{mS} / \mathrm{m}$ - a much lower range than the Mustard and VX pits. The conductivity data are presented on color-contour maps in Figures 13A and 13B.

A review of Figure $13 \mathrm{~A}$ indicates a broad, approximately east/west-trending conductivity minimum between $x=100-270$ and $y=120-150$. This location corresponds to the position of the $\mathrm{RCP}$ as determined from historical aerial photographs. Minimum values, as before, are artifacts of the EM-31 boom/source geometry. The conductivity data indicate that the Riot Control Pit does extend beyond the survey area to the southwest.

Data along the far western portion of the survey area are largely separated from the other data by an area of phragmites. The $\mathrm{x}=100$ profile (Figure 13A) shows two low-conductivity features $(y=100-115$ and $y=130-140)$ that may indicate that the pit branches in two directions at this location. Two sub-parallel trenches were identified in the wooded area west of the survey site. Further evidence of possible trench bifurcation is provided in Sections 4.3 and 4.4.

\subsection{EM-61}

Figure 14 shows a color-contour plot of the lower-coil millivolt survey data, collected at $10-\mathrm{ft}$ intervals along profiles parallel to the $\mathrm{x}$ - and $\mathrm{y}$-axes. The data reveal areas with strong, positive electromagnetic responses generally corresponding to the Riot Control Pit location indicated by the conductivity data. Areas outside of the defined pit, centered at $(126,160)$ and $(268,100)$, also show strong, positive electromagnetic responses. Other anomalies scattered around the northern and eastern perimeters of the site indicate the presence of subsurface metal. 

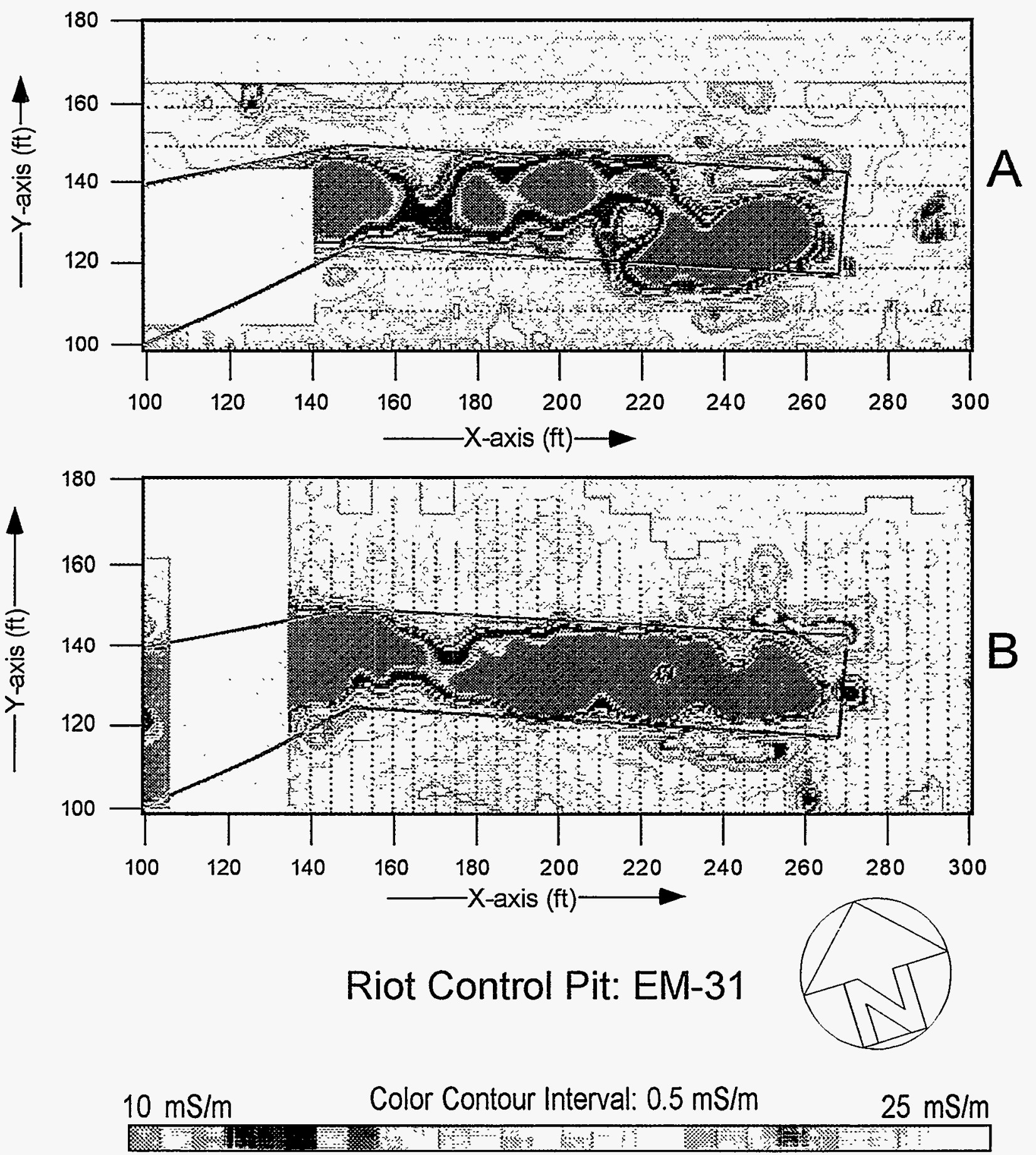

FIGURE 13 EM-31 Electromagnetics Map, Riot Control Pit A: Profiles Parallel to Y-Axis, $\mathrm{B}$ : Profiles Parallel to $\mathrm{X}$-Axis 


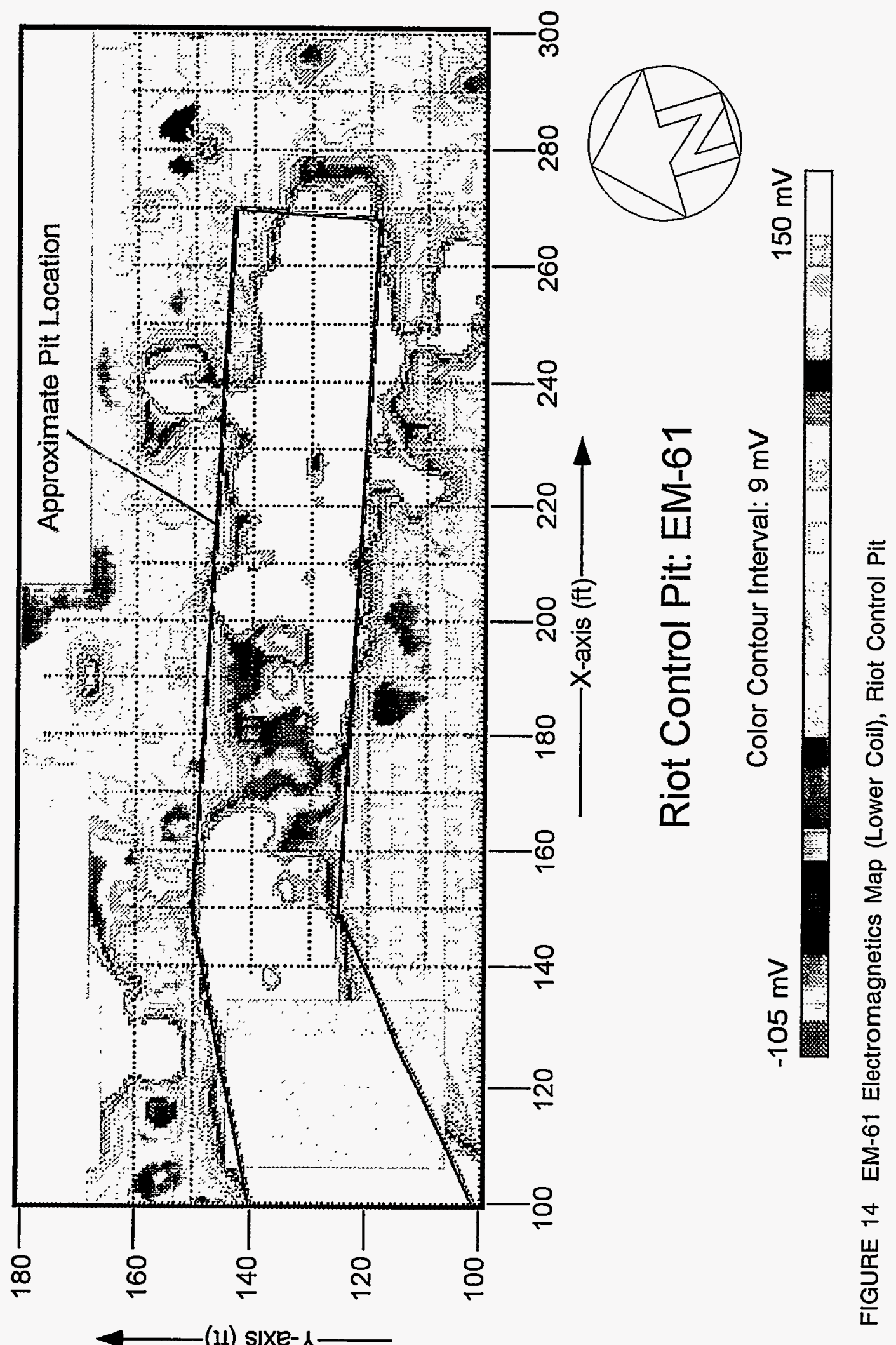




\subsection{Total Field Magnetics}

An east/west-trending, positive magnetic anomaly and a corresponding magnetic low offset to the north define the areal extent of the Riot Control Pit (Figure 15). The location indicated by the magnetic data coincides with the conductivity and electromagnetic data sets. Possible bifurcation of the pit at the western edge of the survey area is indicated by two separate magnetic highs along the 100E profile (Figure 15).

An isolated magnetic anomaly at grid coordinates $(190,170)$ is also shown in the EM-61 data (Figure 14). No surface expression is present at this location, although the vegetation was less dense, allowing ANL to extend the surveys further north at this location.

\subsection{Ground-Penetrating Radar}

GPR profiles were collected along 28 lines at the Riot Control Pit area. The locations and GPR specifications of the profiles are included in Appendix A. Figure 16 shows three GPR profiles parallel to the $y$-axis that cross the western portion of the pit. Figure 16A shows a profile along $x=100$ that is interpreted to show two pits. The conductivity and electromagnetic data provide support for this interpretation; both also indicate a possible bifurcation in the Riot Control Pit at this location. Also, the total width of the EM-61 anomaly associated with the pit is approximately the same as the width occupied by both pits.

Two other GPR profiles (Figures $16 \mathrm{~B}$ and $16 \mathrm{C}$ ) cross the Riot Control Pit along $\mathrm{x}=150$ and $x=200$, respectively. The interpreted location for the pit was determined from changes in reflector character in the GPR profiles, and was further defined using the conductivity, magnetic, and millivolt data sets. The interpreted depth to the bottom of the pit that is shown on the profiles is extremely speculative; if correct, the base of the pit is in the 4- to 5-ft depth range.

Figures 17A, 17B, and 17C show three GPR profiles that cross the eastern half of the Riot Control Pit on the $x=240,260$, and 280 profile lines, respectively. The GPR response of the pit is different at these locations compared to the western section. The reflectors are characterized by higher amplitudes rather than the " $U$ " shapes observed in Figure 16. The maximum width of the pit was determined on the basis of the areal extent of the conductivity, magnetic, and millivolt contoured data, and is displayed as two vertical red bars in Figures 17A and $17 \mathrm{~B}$.

The profile along $x=240$ (Figure 17A) does not provide a clear indication of a pit along the region defined by the contoured data. However, a series of southward-dipping reflectors is observed on the profile from $y=128-135$. At $x=260$ (Figure 17B), the signature of the pit is marked by an abrupt increase in reflector amplitude within the zone defined by the contoured 


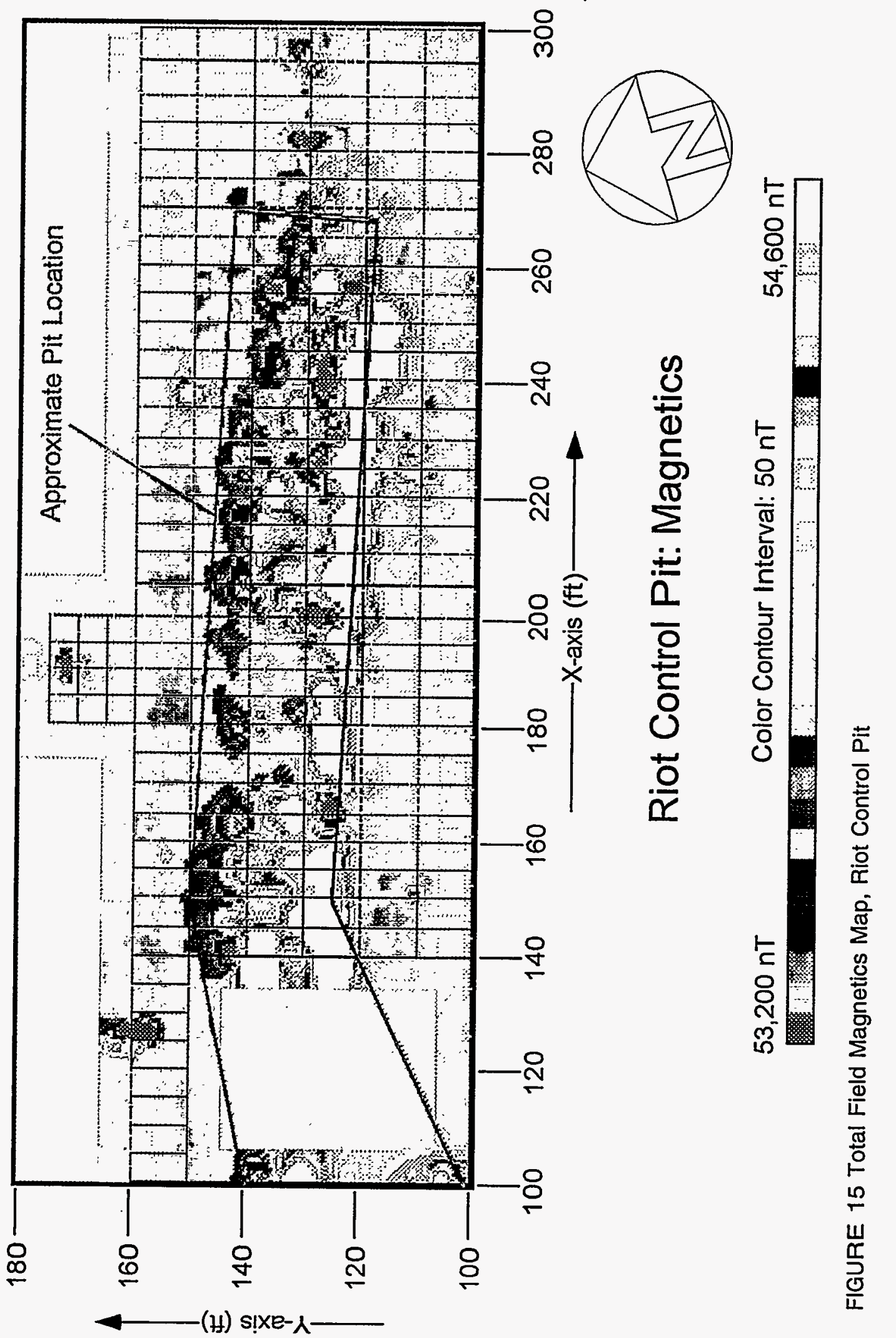




\section{Riot Control Pit: GPR}
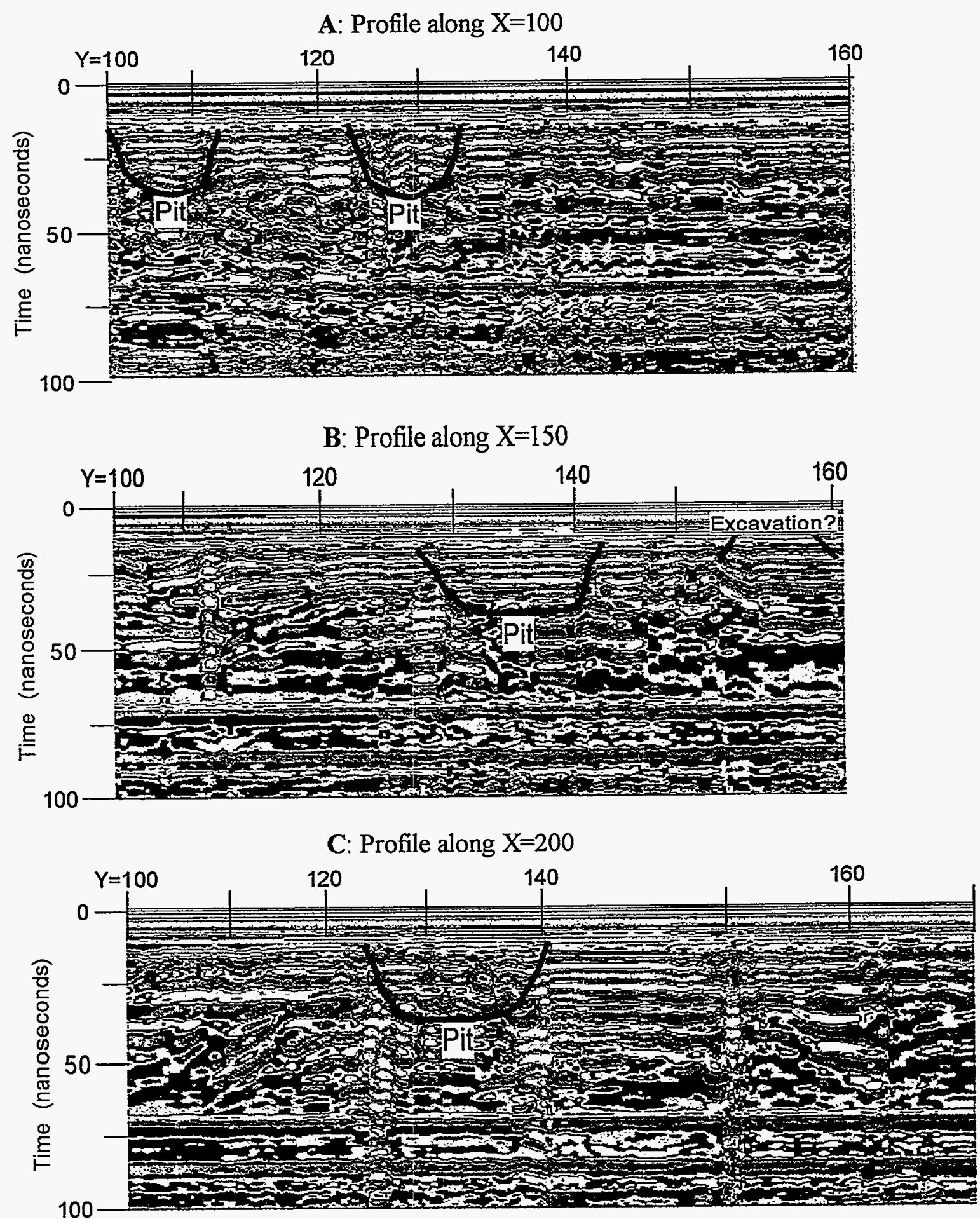

FIGURE 16 GPR Profiles at the Riot Control Pit A: $X=100, B: X=150$, and C: $X=200$ 


\section{Riot Control Pit: GPR}
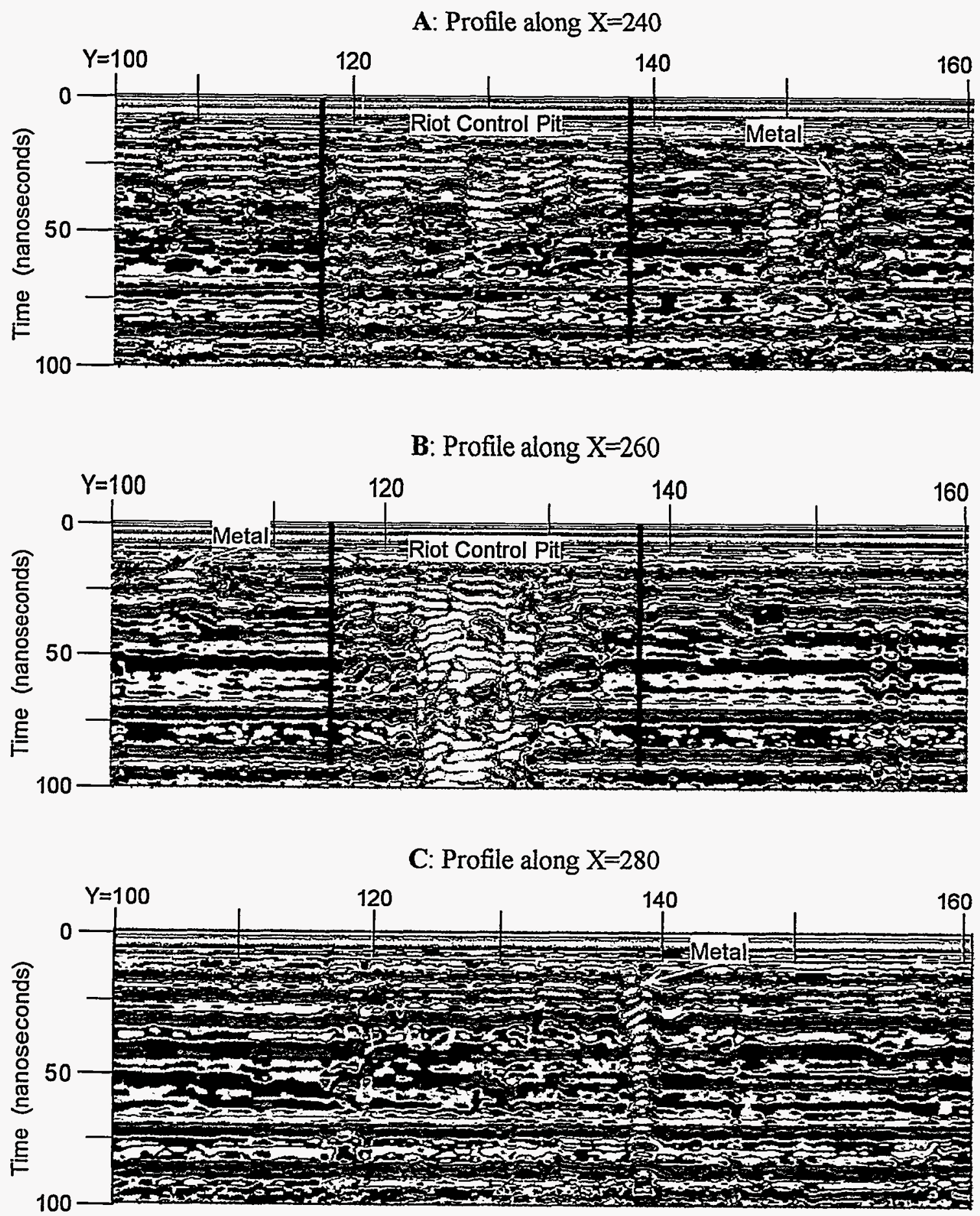

FIGURE 17 GPR Profiles at the Riot Control Pit A: $X=240, B: X=260$, and C: $X=280$ 
data. A series of high-amplitude reflectors at $y=125-130$ extend to the base of the GPR section and are most likely reflection multiples. Truncated reflectors at $y=125$ and $y=130$ most likely mark the north and south limits of the trench. The Riot Control Pit image is not shown on the $x=280$ profile (Figure 17C). This interpretation is consistent with the contoured magnetic, conductivity, and millivolt data, which show a marked decrease in relief at this location.

Figures 18A and 18B present an interpreted and uninterpreted GPR section along the $y=130$ profile corresponding to the inferred center of the Riot Control Pit from $x=150-300$. The interpreted bottom of the pit, shown from $x=150-240$, is defined by the GPR profiles perpendicular to the axis of the trench. The interpreted pit bottom corresponds to a depth at which reflector amplitudes increase slightly. This increase in amplitude is easily traced to the east, where it abuts a 50-ft-wide zone of discontinuous, high-amplitude reflectors $(x=240-290)$. In the far eastern portion of the trench, the reflectors are predominantly high-amplitude and discontinuous and have minimum depths of 1.5 to $2.0 \mathrm{ft}$.

\subsection{Discussion}

The geophysical signatures of the Riot Control Pit are similar to those of the VX and Mustard pits. The conductivity, electromagnetic, and GPR data support the interpretation that different trench building/abandonment events may have occurred along the Riot Control Pit; these may have resulted in separate, discrete pits. The magnetic, conductivity, and GPR data sets reveal evidence of a bifurcation of the pit at the western edge of the survey area, possibly for drainage purposes. The survey did not define the extent of the pit to the west, where evidence of trenching (again, possibly for drainage of the actual burning area) is present.

The narrow size and anomalous nature of the survey area prevent any regional interpretation of conductive or nonconductive groundwater at the Riot Control Pit. The presence of individual metallic anomalies outside of the pit area should be investigated further. 

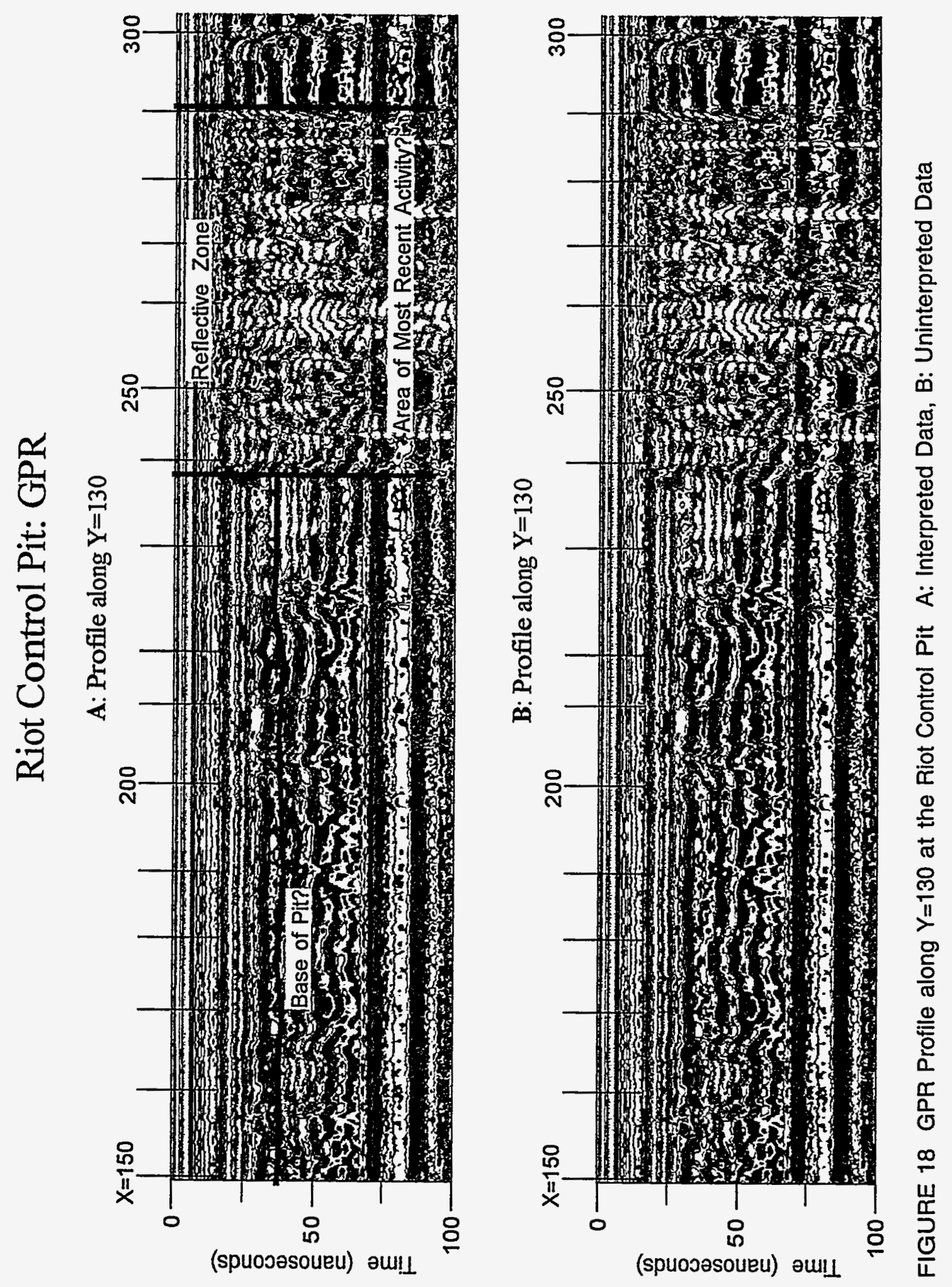


\section{Square Pit Site in TBP Area}

Geophysical surveys were performed at a suspected disposal area approximately $150 \mathrm{ft}$ west-southwest of the main TBP (Figure 2). This PAOC is referred to as the Square Pit Site because of the presence of a partially buried $3.25-\mathrm{ft} \times 4.25-\mathrm{ft}$ steel box. The box is filled with soil to approximately $1 \mathrm{ft}$ below the land surface. The $70-\mathrm{ft} \times 140$-ft survey grid is oriented with the $y$-axis approximately $23^{\circ}$ east of north. The topography slopes gradually toward the southwest; a steeper slope in the southwestern end of the survey area becomes marshland. The box and some barbed wire (fencing?) were found on the surface at the southern edge of the site. Geophysical surveys were performed to determine whether any subsurface features are associated with the Square Pit Site.

\section{$5.1 \quad E M-31$}

Conductivity measurements were collected parallel to the $x$ - and $y$-axes with variable profile spacing concentrated around the Square Pit Site (Figures 19A and 19B). Apparent conductivities ranged between -16 and $16 \mathrm{mS} / \mathrm{m}$. The color-contour maps presented in Figures 19A and 19B have a much lower contour interval ( 5 to $15 \mathrm{mS} / \mathrm{m}$ ) compared to the three burning pit sites because of the relative lack of anthropogenic features; the smaller-scale anomalous features appear with greater color contrast than the previously presented data sets.

An anomalous area around the Square Pit shows a conductivity low bounded by conductivity highs, a consequence of the "artifact" effect. Other anomalies adjacent to the Square Pit to the west and southwest are related to subsurface metallic debris. Conductivities increase toward the topographically lower south end of the survey area. A conductivity low near the southern edge of the survey area centered at $(150,100)$ represents an anomalous feature within the general rise in conductivity to the south. This low is associated with barbed wire at the surface and possibly other buried debris in this area. A small conductivity high was recorded near the northeastern corner of the site $(170,230)$.

\section{$5.2 \quad E M-61$}

Figure 20A presents the lower-coil EM-61 data. The response to the Square Pit dominates the central part of this map. A positive-millivolt anomaly observed at the Square Pit is flanked by low anomalies, which are artifacts of the contouring program. Smaller positivemillivolt anomalies are present at the locations of conductivity lows to the west and southwest of the Square Pit. A broad positive anomaly, centered at coordinates $(150,110)$ in the southern portion of the grid, corresponds to the location of barbed wire observed at the surface. The coildifference data (not shown) reveal a strong positive feature, suggesting a source(s) buried deeper than $1 \mathrm{ft}$ below the surface. 


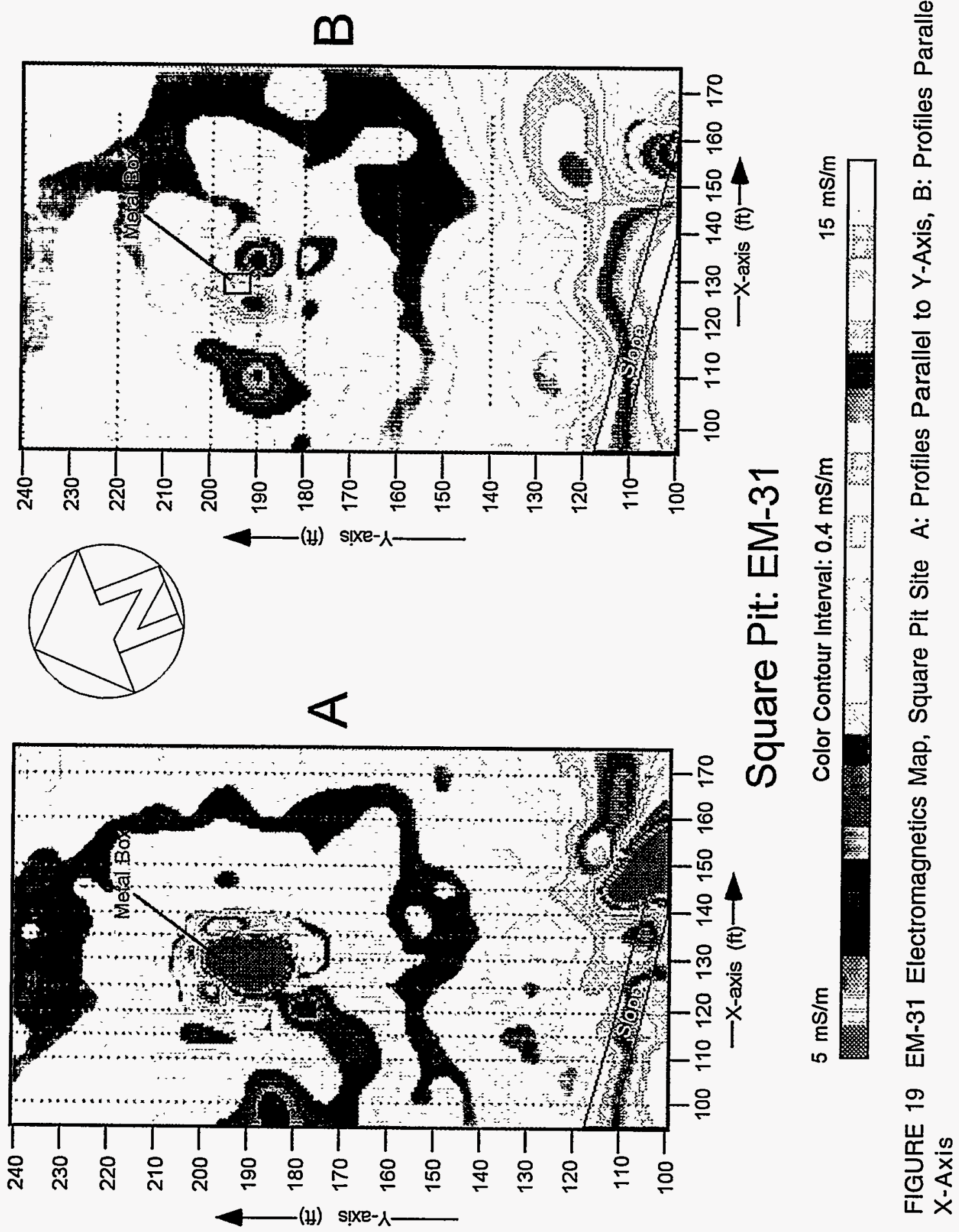




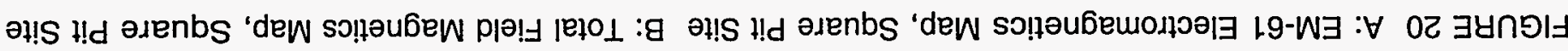

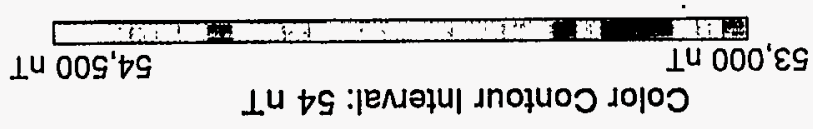

so!fəu6ew :ł!d әлenbs

$\longrightarrow$ (H) $\mathrm{s!xe}-\mathrm{X}$ -

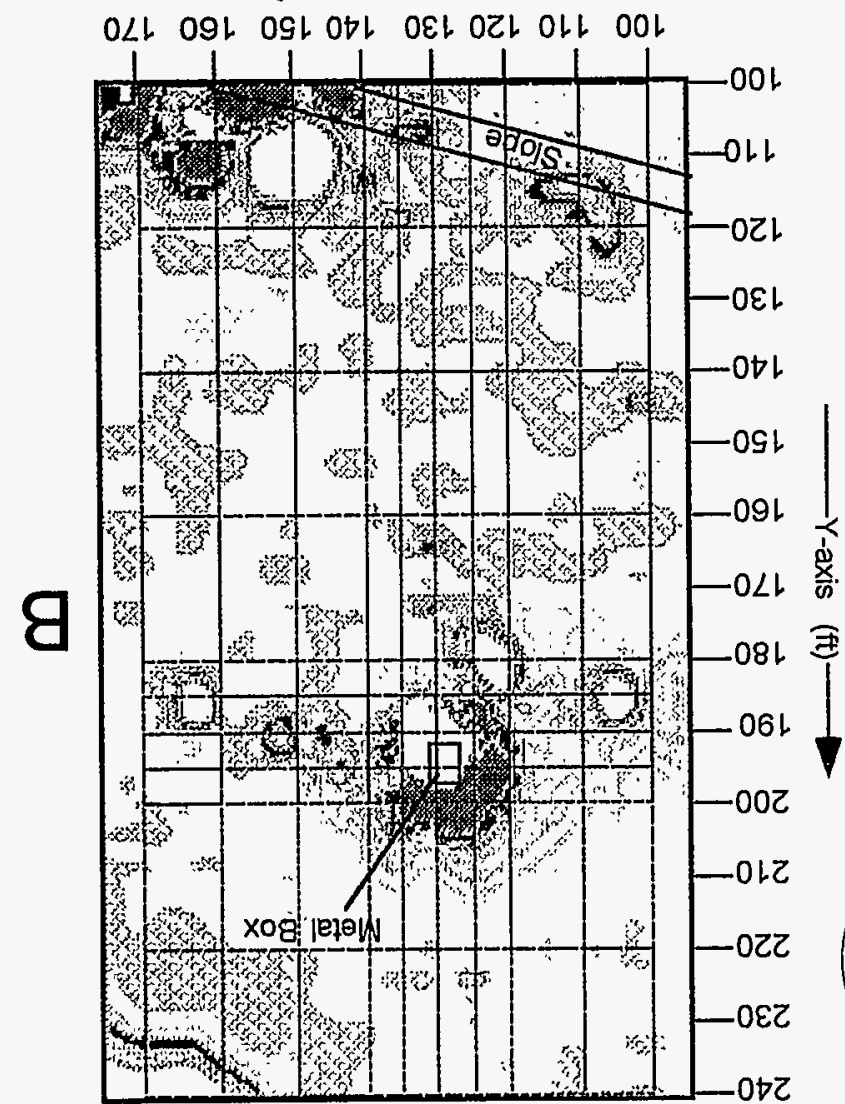

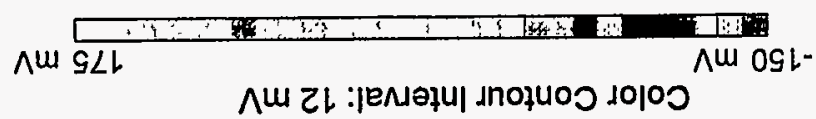

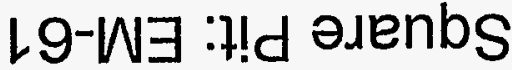

$\longrightarrow$ (H) s!xe-X-

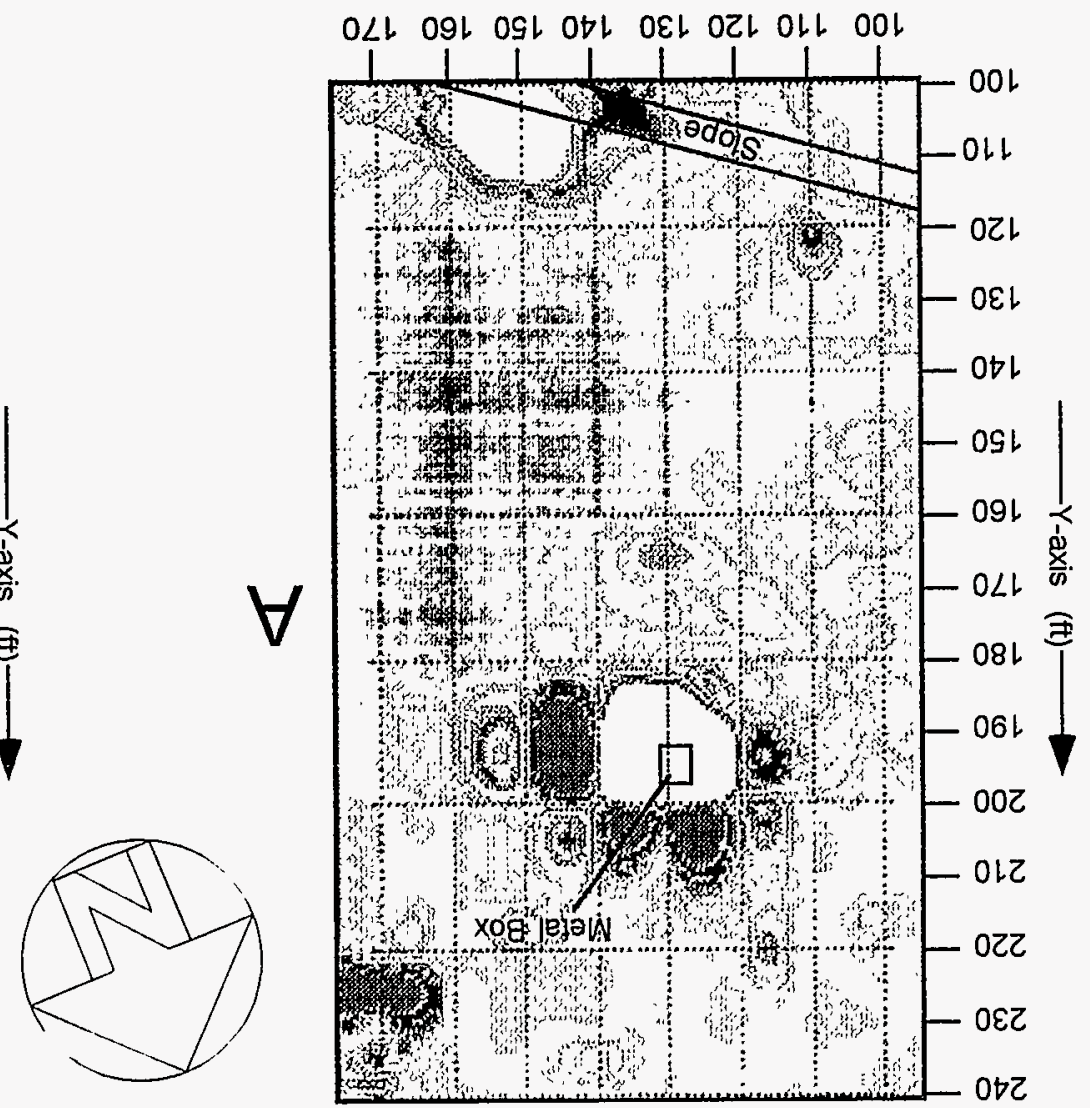


Other isolated electromagnetic anomalies at the site suggest scattered subsurface metallic debris. The magnetic data confirm this interpretation (Figure 20B). A large negative-millivolt anomaly is present at $(170,225)$. No other geophysical data set indicates an anomaly at this location. The cause of this large $(-1,142 \mathrm{mV})$ negative electromagnetic field is not known, but may be related to instrument interference.

\subsection{Total Field Magnetics}

The total field magnetics survey was conducted along variously spaced profiles concentrated near the Square Pit, similar to those used for the EM-31 survey (Figure 20B). The largest magnetic anomalies are associated with the Square Pit and the southern edge of the survey area, where the magnetic signature of the anomalous area indicates the presence of multiple sources. Scattered magnetic anomalies, generally corresponding to the EM-61 anomalies, were also recorded at the site (compare Figures 20A and 20B). The magnetic high in the northeastern corner of the site is associated with a conductivity high and a millivolt high/low pair (not the large negative anomaly previously discussed), but it may also be influenced by monitor well P-9, located just north of the survey grid.

\subsection{Ground-Penetrating Radar}

Thirty-six GPR profiles were collected along the Square Pit grid. The locations and GPR specifications of the profiles are listed in Appendix A. The results of.these surveys did not reveal any subsurface disturbances resembling previous excavation or piping features. Figure 21 shows a GPR profile collected along the $x=100$ profile. The profile shows a generally flat-lying surface and possible buried metallic debris at approximately $(100,190)$, which coincides with anomalies in the other geophysical data sets.

\subsection{Discussion}

No major subsurface disturbance was noted at the Square Pit area. A few buried metallic objects are present in the area. The areas west and southwest of the Square Pit show the greatest concentration of geophysical anomalies. A subtle area of low conductivity in the vicinity of the metal box is an artifact caused by the box and other subsurface metallic debris. Significant magnetic, EM-31, and EM-61 anomalies are present at the southeastern edge of the site. The extent of this anomalous area further into the wetland to the south was not determined. 


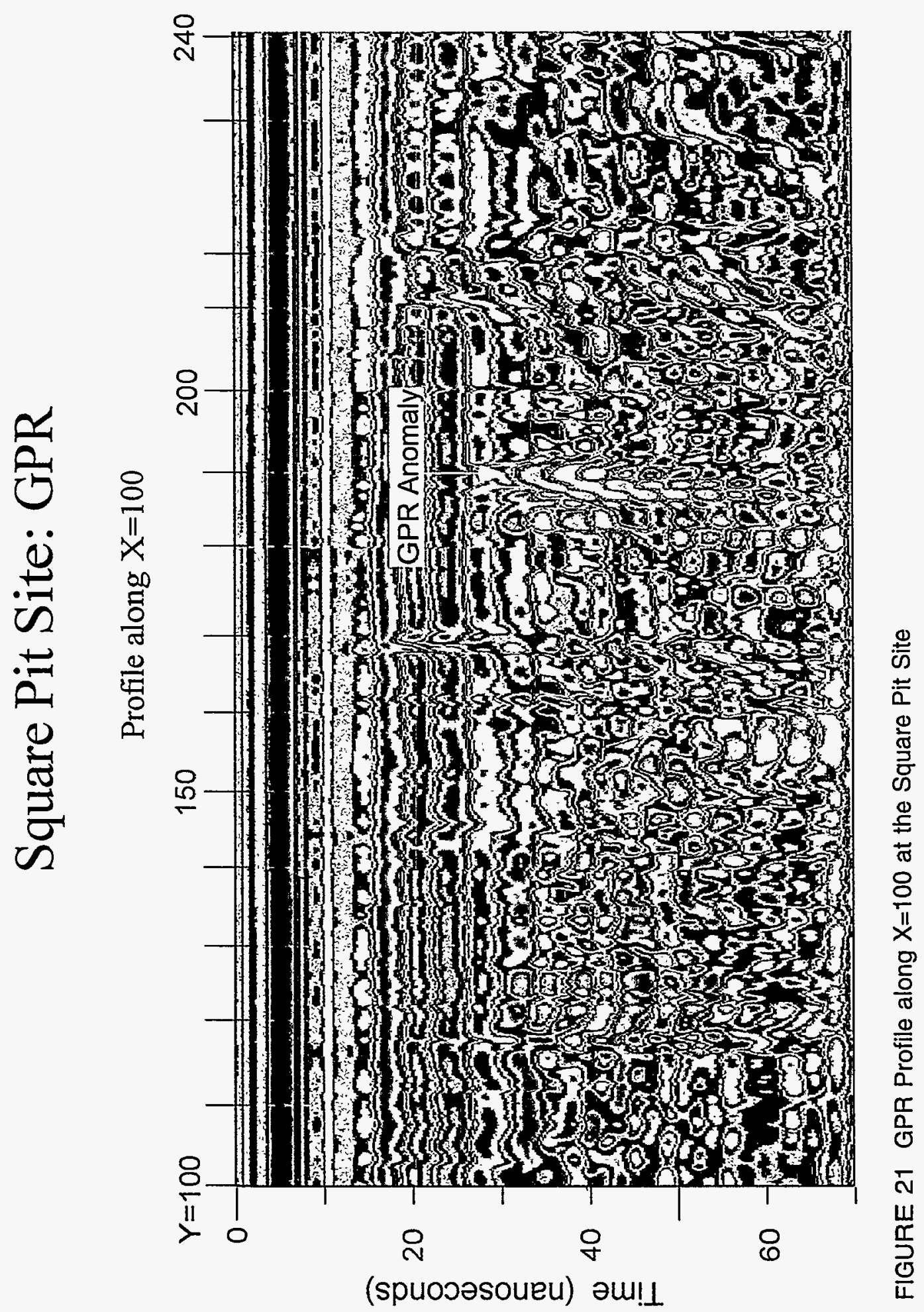




\section{Storage Area near the WPP}

A suspected storage area is located approximately $200 \mathrm{ft}$ southeast of the WPP on the west side of Rickett's Point Road (Figure 2). This relatively flat-lying PAOC contains mounds of soil and debris. The survey grid for this portion of the WPP site measures $80 \mathrm{ft} \times 90 \mathrm{ft}$. The $y$-axis is oriented approximately $26^{\circ}$ east of north and parallel to the adjacent road. A post with a mounted communications box is located at $(165,173)$ on the survey grid.

\section{$6.1 \quad E M-31$}

Conductivity measurements were collected parallel to the $x$-axis with profiles spaced at $10-\mathrm{ft}$ intervals and parallel to the $\mathrm{y}$-axis with profiles at 5 - $\mathrm{ft}$ intervals. A narrow range of measured apparent conductivities, between -5 and $25 \mathrm{mS} / \mathrm{m}$, was found at the suspected storage site. Figures $22 \mathrm{~A}$ and $22 \mathrm{~B}$ present individual maps showing the conductivity data measured in each direction. The approximate location of the mounds (open circles and ovals), visible metal debris (shaded symbols), and the communications post are also indicated on the maps.

A linear conductivity anomaly is present in the eastern portion of each map (Figure 22). The signature of the anomaly suggests that an underground cable leads into and out of the former communications box. The signature stops near the post, either because the cable was cut or because it becomes too shallow to be detected with the EM-31. This anomalous signature presents a good example of the directional properties of the instrument. As seen in the east/west profiles perpendicular to the cable (Figure 22A), the EM-31 signature is a conductivity low bounded by highs on either side. When viewed along profiles parallel to the cable (Figure 23B), the feature appears as a conductivity high.

A few other conductivity anomalies are scattered around the site. Most of these are associated with the debris mounds. Again, spatial variation is evident when viewing the two data sets. A negative anomaly, centered at $(125,129)$ (Figure 22B), was not detected in the other geophysical data sets. The cause of this anomaly is not known but may be related to operator error.

\subsection{EM-61}

Figure 23A shows a color-contour plot of the lower-coil EM-61 data. The communication cable is not visible in the lower-coil data, which reflect the electromagnetic response of a deeper area than the upper coil. This indicates that the depth of the cable is very shallow (less than $1 \mathrm{ft}$ ). A large positive anomaly is present at the location of the post, which extends into the ground. 


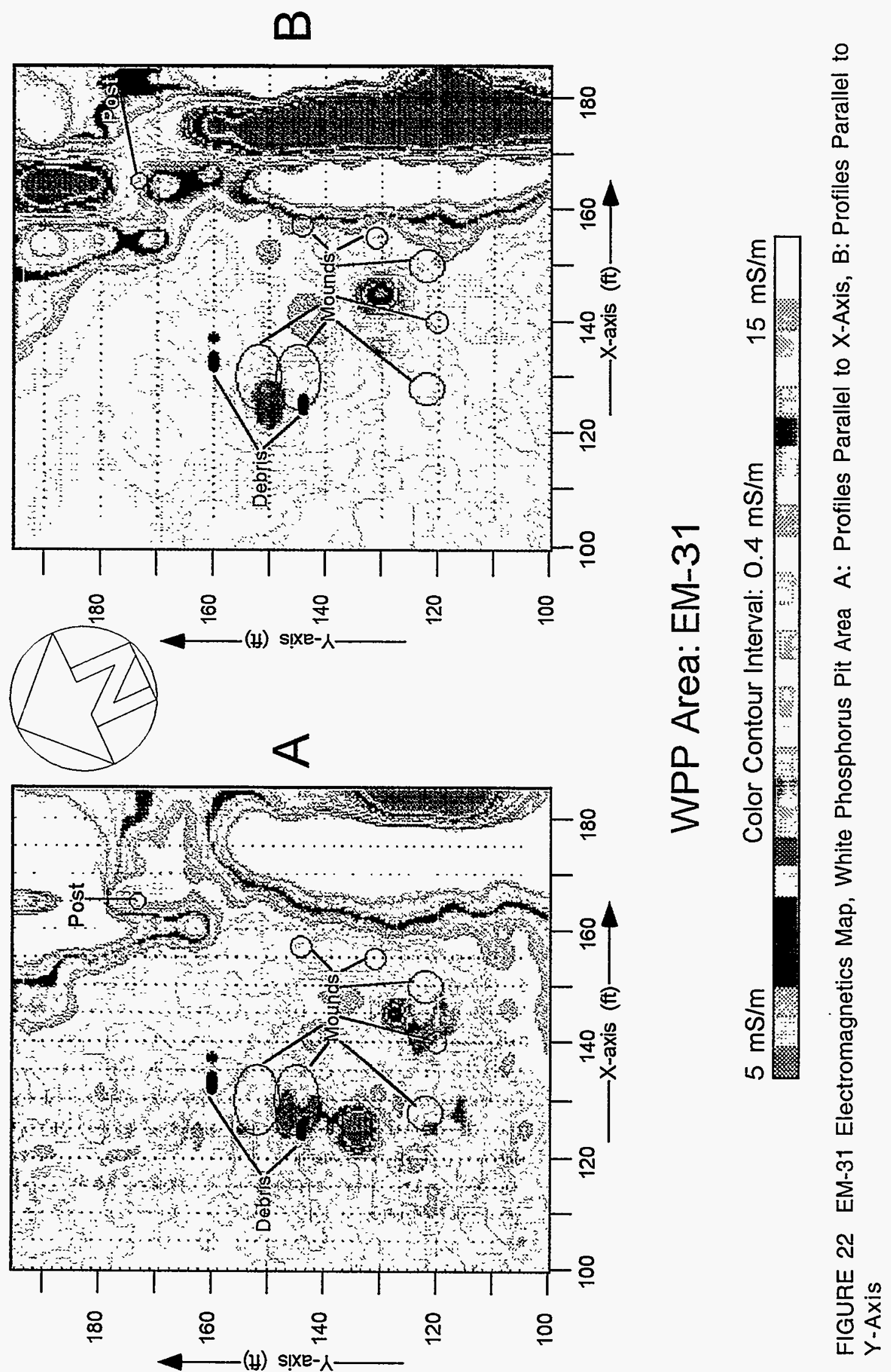




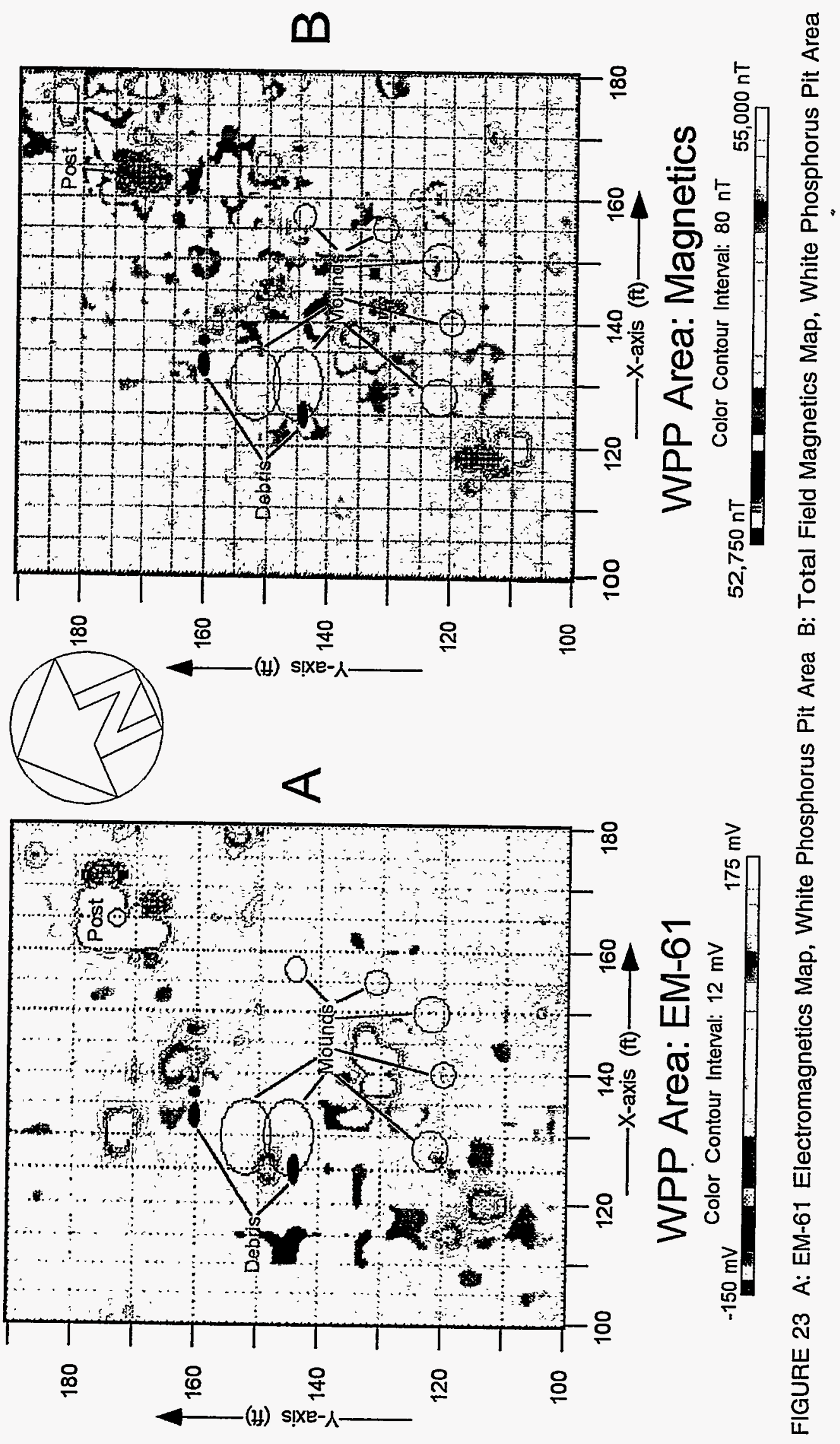


EM-61 anomalies are also scattered around the entire survey area and generally correspond to conductivity and magnetic anomalies. No anomaly trends suggest organized burials in this area. The upper- and lower-coil responses indicate that the majority of the anomalies are buried in the upper 1 to $2 \mathrm{ft}$.

\subsection{Total Field Magnetics}

The color-contour map of the total field magnetic data is shown in Figure 23B. These data reveal a complex pattern of anomalies. Some of these, especially those that appear at regular intervals along the profile line, are caused by interference from the steel-toed boots worn by the operator at this site.

The source of a paired anomaly, with center at $(165,180)$, is most likely the post located in this area. No surface sources were observed for two other magnetic anomalies in this area, one immediately east of the post and the other northeast of the post; these are probably caused by buried (shallow) ferrous debris. Other paired anomalies, with centers at $(117,115),(140,133)$, and $(165,150)$ (Figure 23B), are also not associated with surface features but probably have shallow metallic sources. These anomalies correspond to anomalies in the EM-61 data (see Figure 23A).

\subsection{Ground-Penetrating Radar}

Nineteen GPR profiles were collected along the WPP survey grid. The locations of the GPR profiles are listed in Appendix A. The GPR data did not reveal the presence of buried debris at this site, but the location of the dirt mounds hampered both the collection and interpretation of the GPR data. Changes in antenna elevation when crossing the dirt mounds resulted in apparent changes in the depth and continuity of individual reflectors in the GPR profile section. No GPR profile for the WPP site is presented here.

\subsection{Discussion}

Conductivity anomalies associated with a utility post are most likely caused by a buried cable (or utility line). The geophysical data do not indicate the presence of other, more deeply buried items (greater than $2 \mathrm{ft}$ ). The observed scattered anomalies in the magnetic and millivolt data could be explained by metallic items at depths less than $2 \mathrm{ft}$. No evidence of organized burials was revealed by the magnetics, EM-61, or GPR surveys in the WPP area. 


\section{Exploratory Profiles}

Exploratory profiles were conducted at three PAOC sites at J-Field using the four geophysical methods employed at the five survey sites described in Sections 2 through 6 . The PAOC areas included the following: a suspected trench west of the South Beach Trench; a suspected filled trench in the Ruins Site northeast of the WPP; and Site XI, west of Rickett's Point Road in the northwestern part of J-Field (\#6 through \#8, respectively, on Figure 2). The locations for the exploratory profiles were determined on the basis of historic aerial photographs at J-Field. The aerial photographs indicated that undocumented activities had occurred at the three PAOCs. Figure 2 shows the approximate locations of the exploratory profiles. The length of each exploratory profile is indicated in Appendix A. Figures 24 through 27 present EM-31, EM-61, and magnetics data from each of the three sites. The data are aligned vertically for each profile line to allow a comparison of anomaly positions for each of the three geophysical methods. The conductivity data were recorded at the receiver position, resulting in an approximate 5-ft offset in the true measurement position. The figures show the corrected positions of the conductivity data.

\subsection{Suspected Trench near South Beach Trench Site}

The suspected trench is located west of the South Beach Trench in the southwestern portion of J-Field (\#6, Figure 2). Three parallel, 50-ft-long profiles were collected along approximate south-to-north transects at the site. The profiles were centered over the former trench and proceeded from east (profile 1) to west (profile 3). Figure 24 presents the EM-31, EM-61, and magnetometer data for the three profile lines at the suspected trench. No GPR anomalies were noted along the three profiles.

In general, the EM-31 conductivity measurements collected at the suspected trench (top row, Figure 24) indicate lower conductivity toward the north along each profile line. This trend is probably caused by an increase in the depth to the water table. Profiles 1 and 3 exhibit the greatest relief. The EM-61 and magnetics data reveal the presence of buried metallic objects along each profile. As shown in Figure 24, the positions of some anomalies are the same across geophysical methods, while other anomalies do not correlate well between data sets. It is difficult to determine trends on the basis of the limited data but, in general, anomalous zones are present in the three data sets near the beginnings of the profiles and at approximately $30 \mathrm{ft}$ along the profiles. This spatial arrangement would be consistent with a trench-type feature and associated metallic debris. 


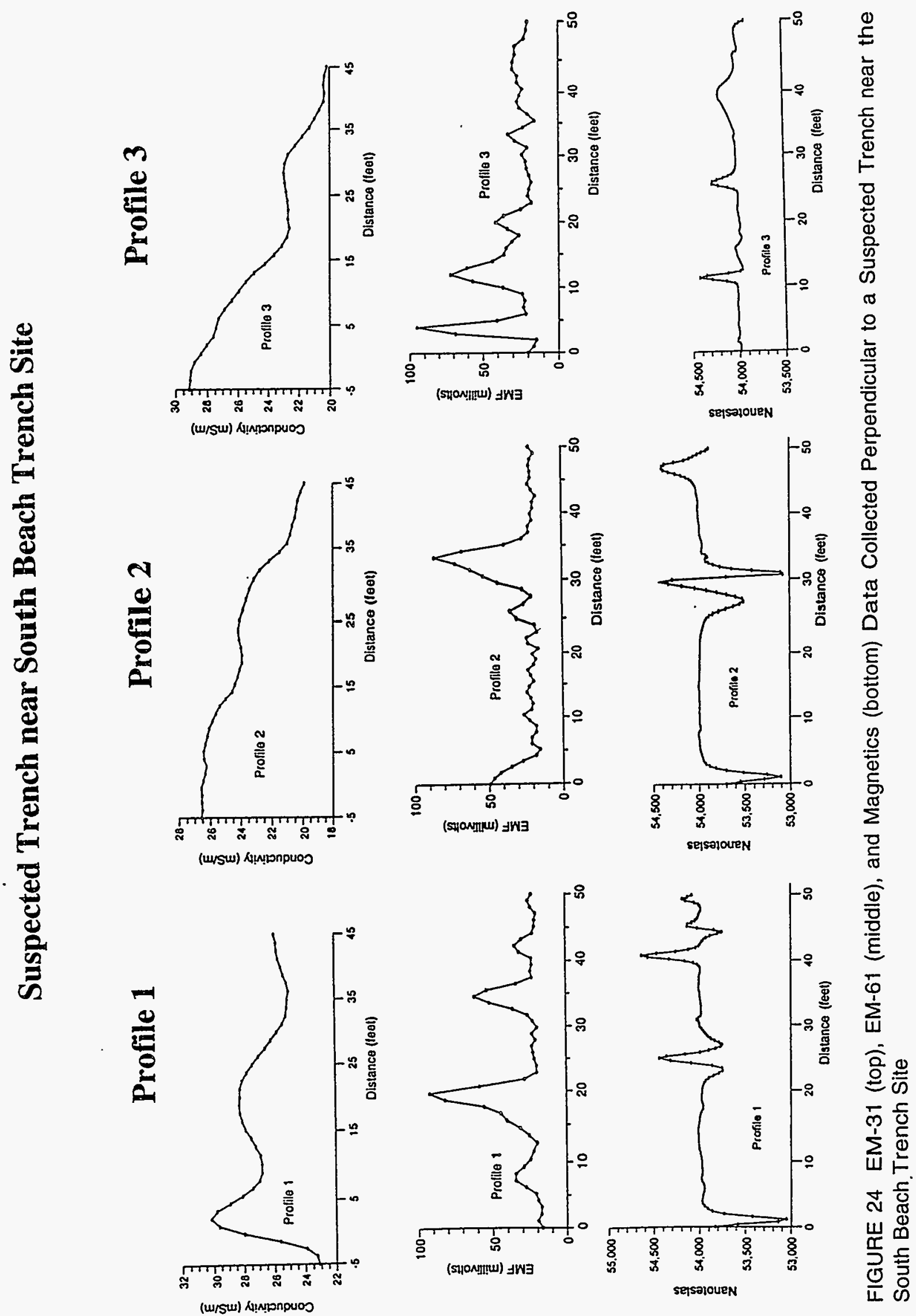




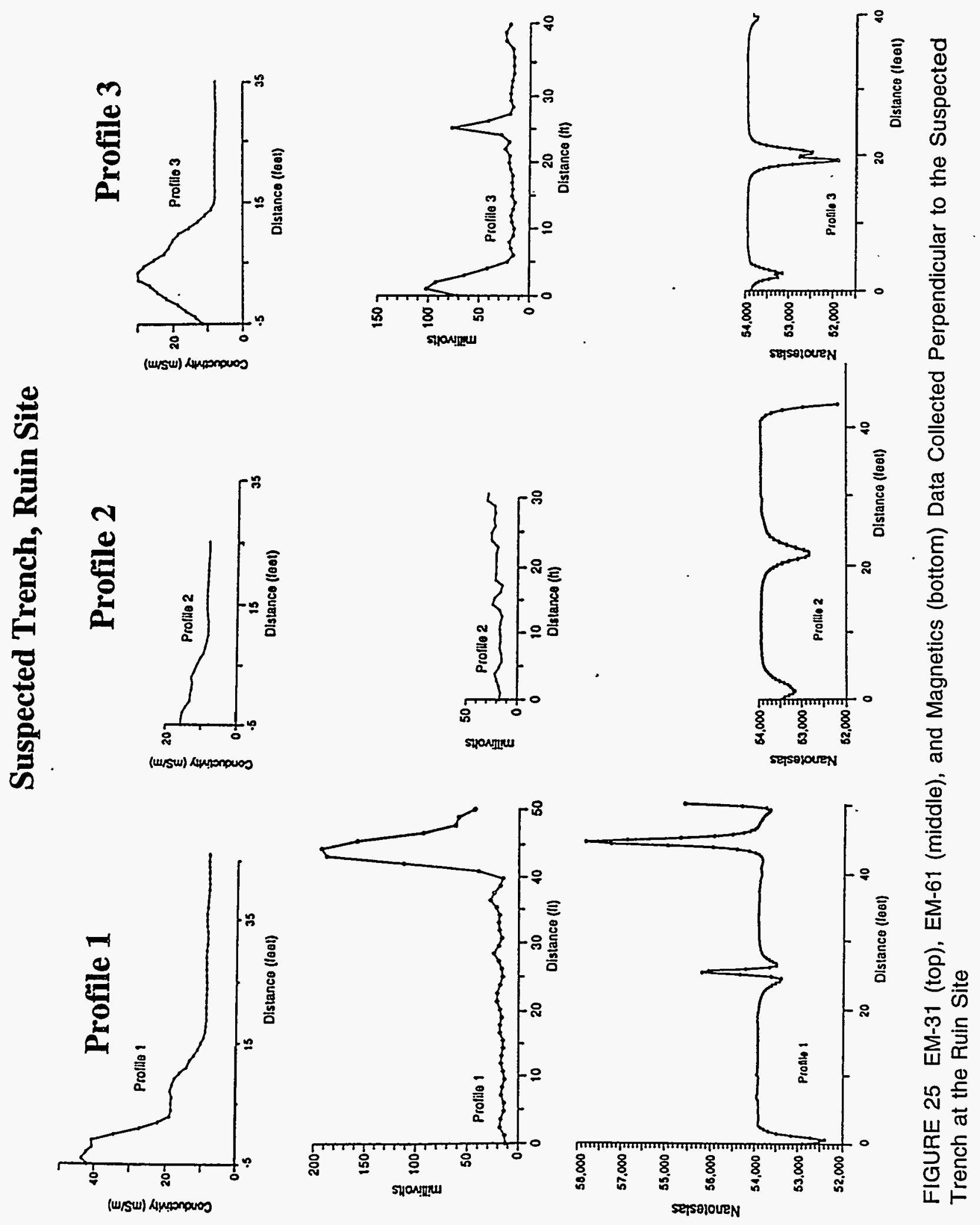




\section{Site}

\section{Profile 1}
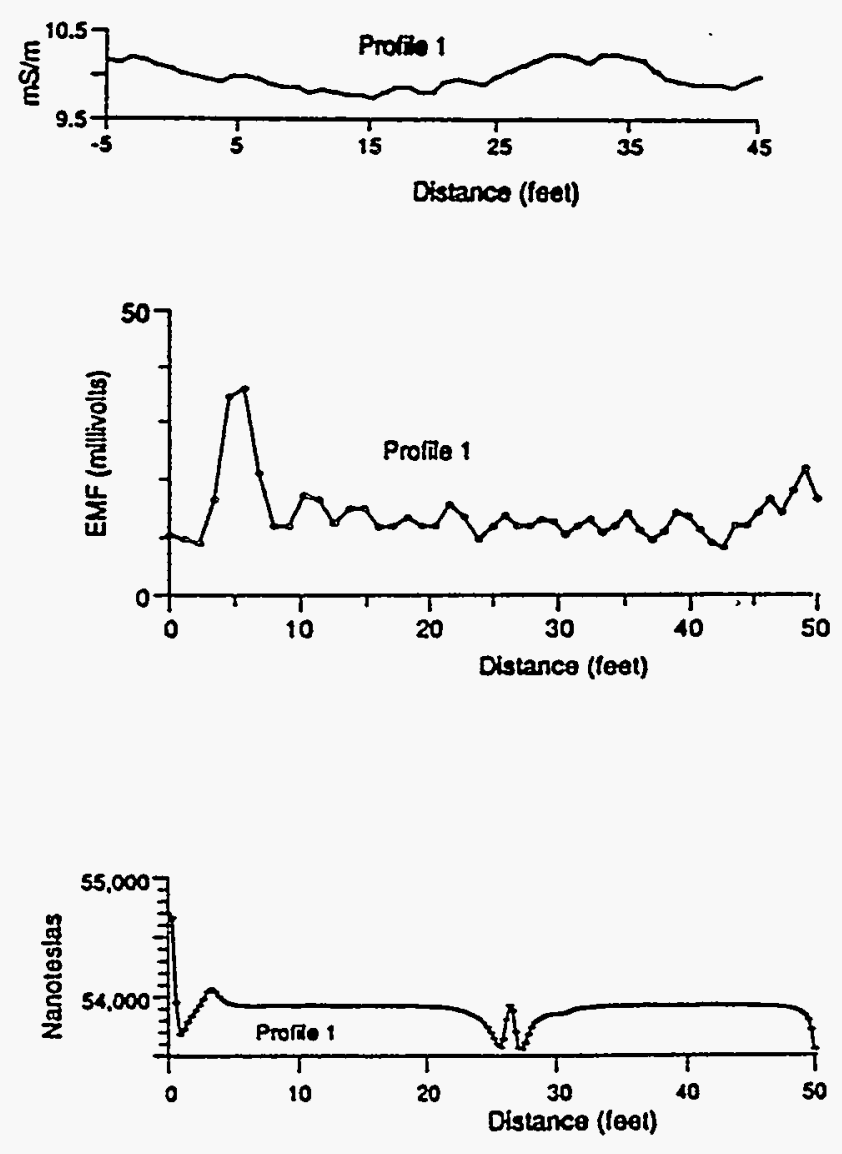

Profile 2
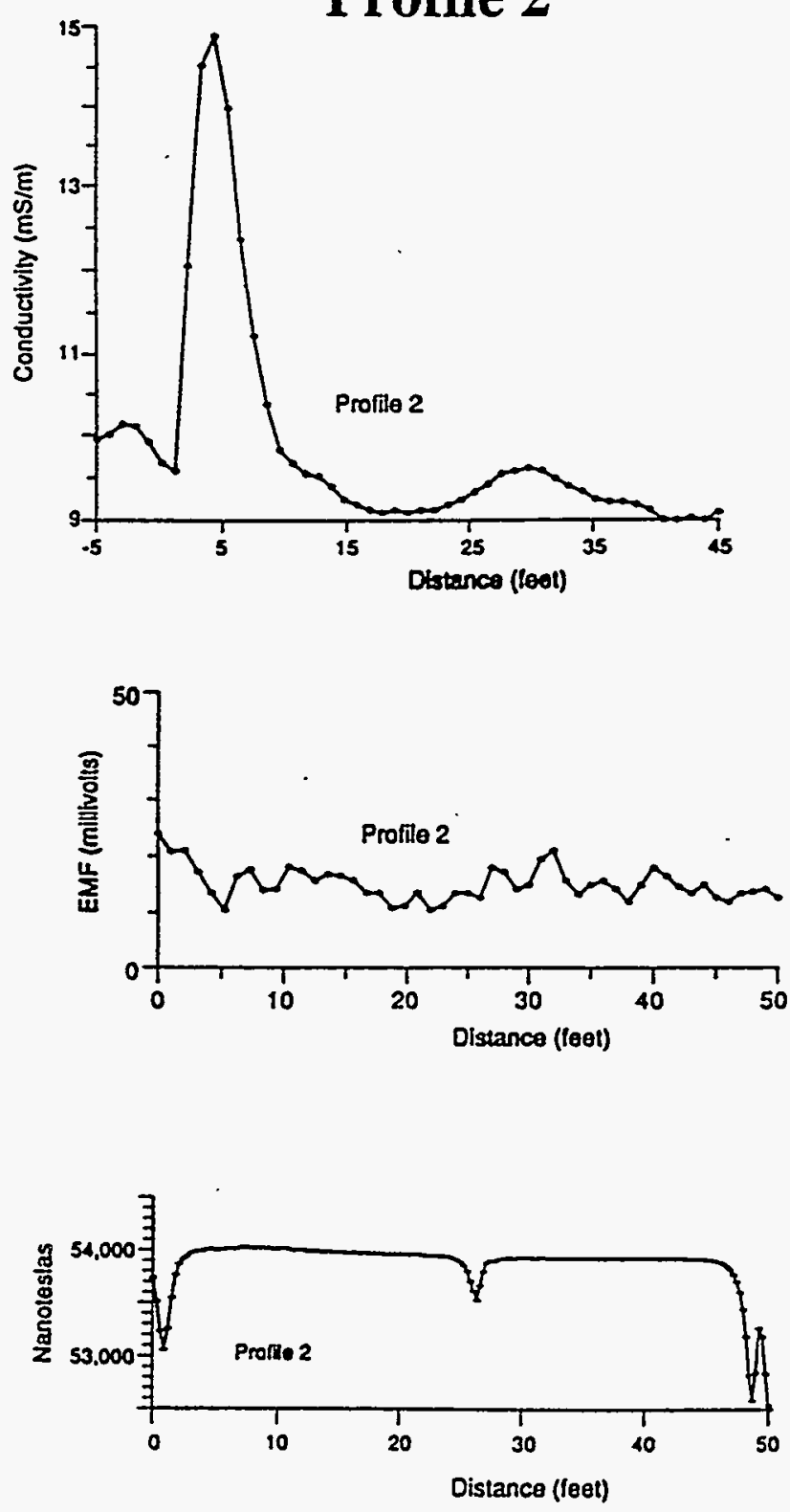

FIGURE 26 Exploratory Profiles Collected at X1 Site: EM-31 (Top), EM-61 (Middle), and Magnetic (Bottom) Data - Profiles 1 and 2 from West to East 


\section{Site}

\section{Profile 3}
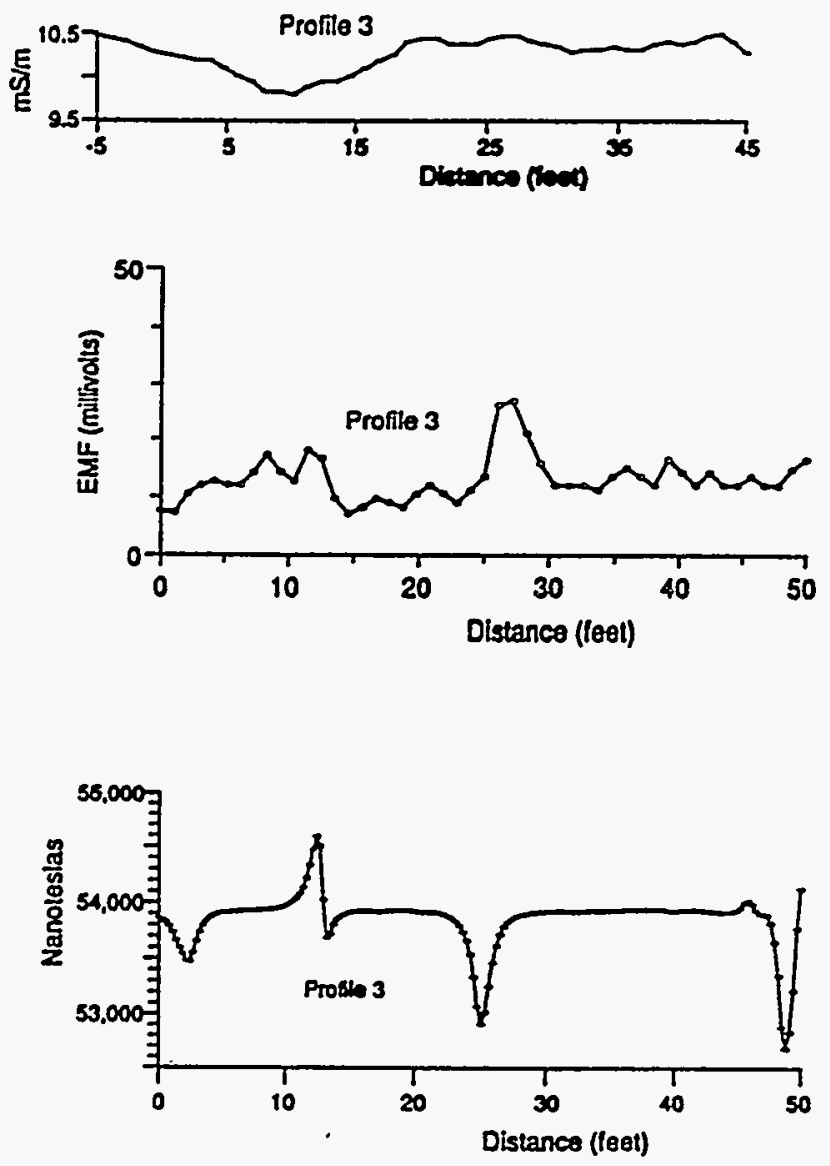

\section{Profile 4}
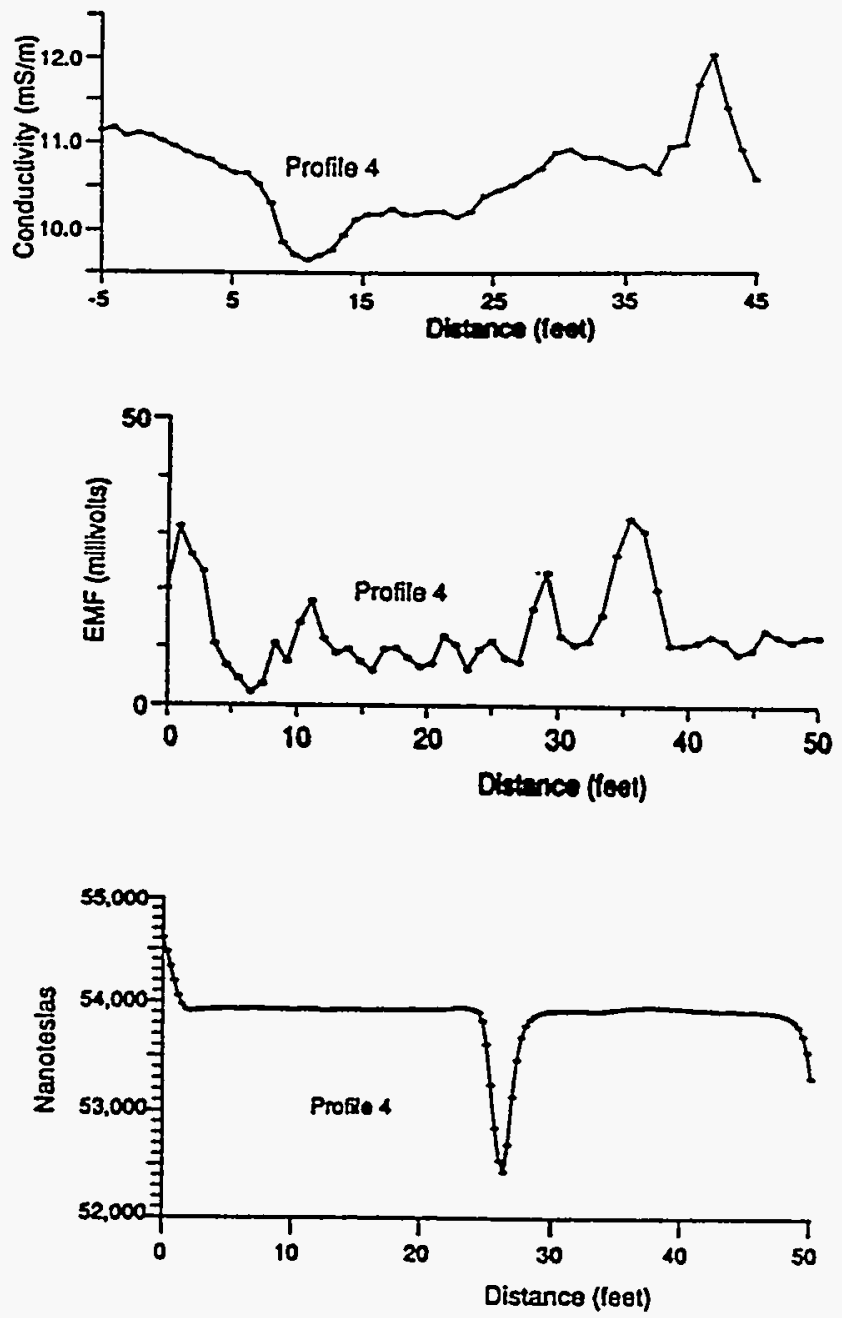

FIGURE 27 Exploratory Profiles Collected at X1 Site: EM-31 (Top), EM-61 (Middle), and Magnetic (Bottom) Data - Profiles 3 and 4 from South to North 


\subsection{Suspected Filled Trench at Ruin Site}

A linear feature that could potentially have been a trench was observed in historic aerial photographs near the Ruin Site northeast of the WPP at J-Field (\#7, Figure 2). Three parallel profiles of varying lengths were collected over the suspected feature. The profiles were performed along southwest-to-northeast transects (profiles 1, 2, and 3 on Figure 2). The feature of interest is no longer apparent at the surface. Figure 26 presents the EM-31, EM-61, and magnetometer data for the three profile lines. No GPR anomalies were recorded along the three profiles collected at the suspected filled trench.

Two anomalies were noted in the conductivity data (top row, Figure 25). The first, a conductivity high, is present at the beginning of profile 1 . The entire anomalous response is not shown. The edge of a magnetic anomaly is also present at the beginning of profile 1 . No EM-61 anomaly is present, probably because the actual source position is before the beginning of the line. The second conductivity anomaly is a broad conductivity high centered at approximately $5 \mathrm{ft}$ along profile 3. Magnetic and EM-61 anomalies at this approximate position indicate the presence of subsurface metal.

The magnetic profile data are somewhat consistent along the three profiles (bottom row, Figure 25). Anomalies were recorded near the beginning, at approximately $20 \mathrm{ft}$, and near the end of the three profiles. Some of these correlate with EM-61 millivolt data (middle row, Figure 25). A relatively large magnetic anomaly that correlates with a millivolt anomaly is present at approximately $45 \mathrm{ft}$ along profile 1 . An anomaly near the beginning of profile 3 was also observed in both data sets. The lack of correlation between the central magnetic anomalies and the EM-61 data, except possibly in profile 3, may indicate that a nonmetallic source, such as amphibolite roadfill material, may cause these particular anomalies. Some subsurface metal, however, is present at the suspected trench site.

\subsection{Site $\mathrm{X} 1$}

Site X1 is located in the northwestern portion of J-Field (\#8, Figure 2). Aerial photographs indicated unexplained disturbances at this location. ANL surveyed two 50 - $\mathrm{ft}$-long profiles at each of two areas to further investigate Site X1. Two parallel profiles (profiles 1 and 2) were collected from west to east in the first area, located south of an old access road approximately $75 \mathrm{ft}$ west of Rickett's Point Road. Two parallel profiles (profiles 3 and 4) were collected from south to north at the second area, located approximately $50 \mathrm{ft}$ west of the first area (see Figure 2).

The conductivity, millivolt, and total field magnetics data for profiles 1 and 2 are presented as Figure 26 . A $5-\mathrm{mS} / \mathrm{m}$ conductivity anomaly was recorded at approximately $5 \mathrm{ft}$ along profile 2 , and a positive electromagnetic anomaly was observed at approximately $5 \mathrm{ft}$ along profile 1 . The magnetic data indicate anomalies near the beginning, center, and end of each profile, 
similar to the Ruin Site profiles. The source(s) of the anomalies is not known. No GPR anomalies were detected in profiles 1 and 2 .

The conductivity, millivolt, and magnetics data for profiles 3 and 4 are presented in Figure 27. A subtle conductivity high was recorded about $43 \mathrm{ft}$ along profile 4 . The electromagnetic data indicate the presence of small anomalies along both profiles. The magnetic data indicate anomalies at the beginning of each profile and at $12 \mathrm{ft}$ along profile 3 ; these may be related to a soil mound at this location. Other magnetic anomalies detected at approximately $25 \mathrm{ft}$ and at both ends of profiles 3 and 4 may be related to the east/west-trending old site access road. No GPR anomalies were detected along profiles 3 and 4 . 


\section{Summary and Conclusions}

Chemical agents and munitions have been destroyed at J-Field by open burning and open detonation at least since World War II. A review of historic aerial photographs (with limited resolution) and subsequent site reconnaissance indicated areas of activity that require further evaluation (Benioff et al. 1995). Records of disposal sites and the types of material disposed of are incomplete. Nonintrusive geophysical exploration techniques were particularly appropriate in investigating the nature of J-Field burial and disposal practices because of the possible presence of unexploded ordnance.

ANL conducted a series of geophysical surveys to determine the position of three known disposal pits and to help characterize five other potential areas of concern at J-Field. Four geophysical techniques (EM-31 and EM-61 electromagnetics, total field magnetometry, and GPR) were found to provide excellent diagnostic capabilities. The limitations of each method were minimized by comparing the complementary data sets. The data quality obtained at the five intensively surveyed sites was also improved by clearing the overgrowth in these areas, which allowed more accurate mapping of small-scale features. The limited size of the survey area, usually constrained at the perimeter by overgrowth, along with the large amounts of metallic debris, made ANL's goal of identifying the extent of subsurface contamination near the trenches largely unattainable. The following specific conclusions were drawn on the basis of survey results:

- The locations of the Mustard, VX, and Riot Control Pits have been delineated. The western boundary of the RCP was found to extend beyond the survey area to a wooded area, where remnants of the pit are still visible. The EM-31 signature of each pit included a conductivity minimum bounded by positive conductivity anomalies. This is a typical EM-31 signature for buried, elongated metal objects where EM profiles are oriented perpendicular to the buried object. The magnetometer and EM-61 surveys indicated the presence of subsurface metal debris within each trench and scattered around each survey area. The three geophysical methods guided the interpretation of the GPR data.

- Studies at the Square Pit Site indicate no large burials or piping associated with the metal box. Subsurface metallic debris is scattered around the Square Pit and the southeast end of the site.

- No evidence of extensive burials was found at the storage area near the WPP. However, a few shallow, buried, metallic objects are scattered throughout this site.

- Subsurface metallic objects were detected at each of the exploratory profile sites. The widely spaced profiles do not allow determination of the nature and 
extent of the detected anomalies. Geophysical surveying at the three exploratory sites, on the scale used at the five sites described above, would require extensive vegetation removal. ANL recommends that, if additional geophysical surveying is required at one of these or another PAOC site(s) at $\mathrm{J}$-Field, a larger grid spacing ( $20 \mathrm{ft}$ to $50 \mathrm{ft}$ ) be employed; this would require less extensive vegetation removal and allow surveying of a larger area. If features were discovered by using regional profiling, more detailed surveys could be conducted to define the extent of the features. 


\section{References}

Benioff et al., 1995, Remedial Investigation Sampling and Analysis Plan for J-Field, Aberdeen Proving Ground, Maryland, ANL/EAD/TM-38, Vol. 1, Argonne National Laboratory, Argonne, Ill.

Bennett, R.R., and R.R. Meyer, 1952, Geology and Ground-Water Resources of the Baltimore Area, Bulletin 4, Maryland Department of Geology, Mines, and Water Resources.

Colman, S.M., et al., 1990, Ancient Channels of the Susquehanna River beneath Chesapeake Bay and the Delmarva Peninsula, Geological Society of America Bulletin, Vol. 102, p.1268-1279.

Cordell, L., et al., 1992, Potential Field Geophysical Software: Version 2, U.S. Geological Survey Open-File Report 92-18.

Daudt, C.R., et al., 1994, Environmental Geophysics at J-Field, Aberdeen Proving Ground, Maryland, ANL/ESD/TM-77, Argonne National Laboratory, Argonne, Ill.

Davies, B.E., et al., 1995, Environmental Geophysics at Kings Creek Disposal Site and 30th Street Landfill, Aberdeen Proving Ground, Maryland, ANL/ESD/TM-83, Argonne National Laboratory, Argonne, Ill.

Dingman, R.J., et al., 1956, The Water Resources of Baltimore and Harford Counties, Bulletin 17, Maryland Department of Geology, Mines, and Water Resources.

Geonics Limited, 1992, EM-31 Operating Manual (for Models with Two Digital Meters), Mississauga, Ontario.

GSSI, 1987, Operations Manual for Subsurface Interface Radar System-3, North Salem, N.H.

Hughes, W.B., 1991, "Application of Marine-Seismic Profiling to a Groundwater Contamination Study, Aberdeen Proving Ground, Maryland," Groundwater Monitoring Review 11(1):97-102.

Hughes, W.B., 1993, Hydrogeology and Soil Gas at J-Field Aberdeen Proving Ground, Maryland, Water Resources Investigation 92-4087, U.S. Geological Survey, Towson, Md.

Kehrin, R.T., et al., 1988, The Surficial Sediments of the Chesapeake Bay, Maryland - Physical Characteristics and Sediment Budget, Report No. 48, Maryland Geological Survey, Towson, Md. 
McGinnis, L.D., et al., 1994a, Environmental Geophysics of the Pilot Plant on the West Branch of Canal Creek, Aberdeen Proving Ground, Maryland, ANL/ESD/TM-74, Argonne National Laboratory, Argonne, 111.

McGinnis, L.D., et al., 1994b, Environmental Geophysics at Beach Point, Aberdeen Proving Ground, Maryland, ANL/ESD-23, Argonne National Laboratory, Argonne, Ill.

Oliveros, J.P., and D.A. Vroblesky, 1989, Hydrogeology of the Canal Creek Area, Aberdeen Proving Ground, Maryland, Water Resources Investigation Report 89-4021, U.S. Geological Survey, Towson, Md.

Otton, E.G., and R.J. Mandle, 1984, Hydrogeology of the Upper Chesapeake Bay Area, Maryland, with Emphasis on Aquifers in the Potomac Group, Report No. 39, Maryland Geological Survey, Towson, Md.

Southwick, D.L., J.P. Owens, and J. Edwards, Jr., 1969, The Geology of Harford County, Maryland, Maryland Geological Survey, Towson, Md.

Thompson, M.D., 1994, COLORMAP software, unpublished. 
Appendix A:

GPR Profile Line Coordinates and Settings 
Ground Penetrating Radar Profiles J-Field January 1995

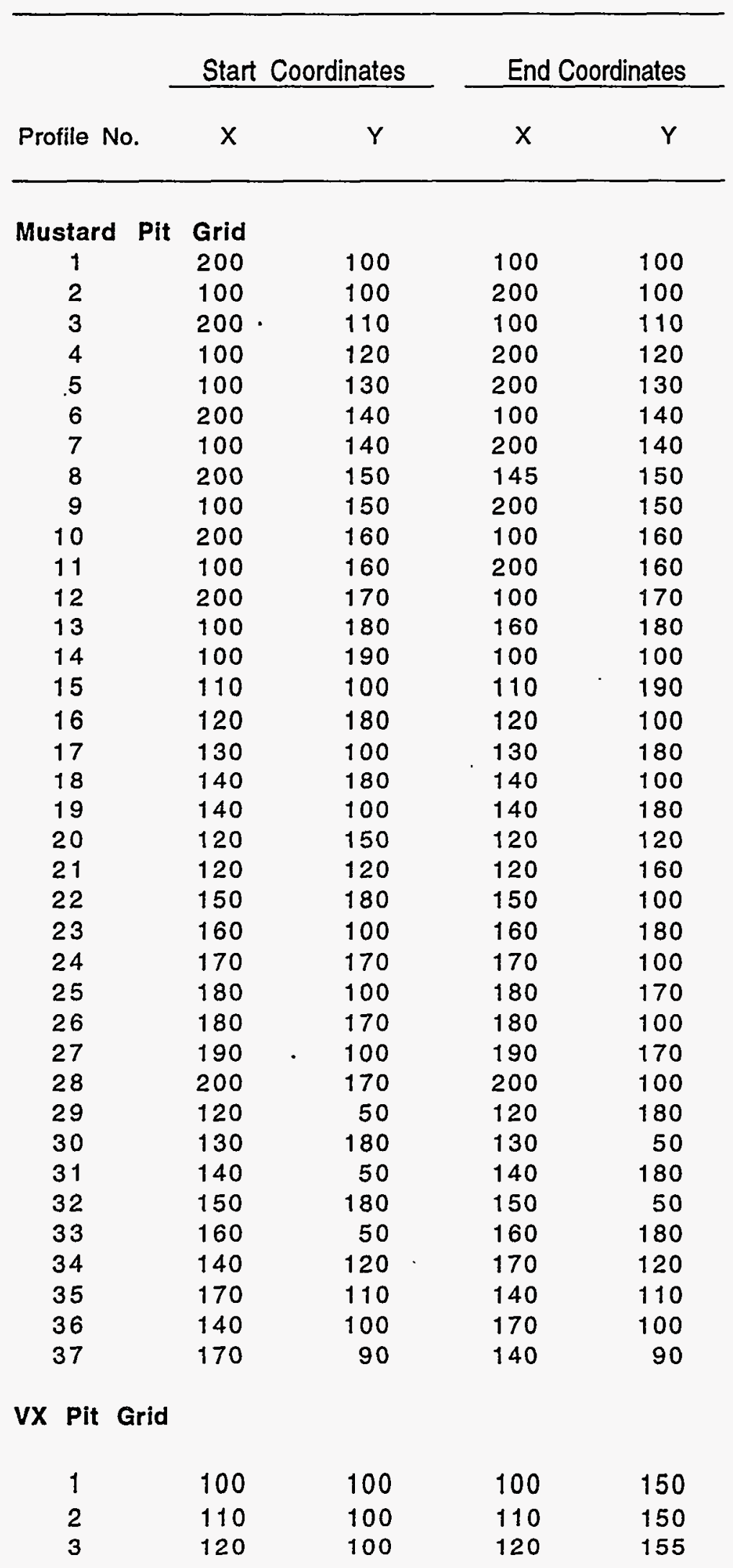




\section{Ground Penetrating Radar Profiles (Cont.) J-Field January 1995}

\begin{tabular}{|c|c|c|c|c|c|}
\hline \multirow[b]{2}{*}{ Profile } & \multirow[b]{2}{*}{ e No. } & \multicolumn{2}{|c|}{ Start Coordinates } & \multicolumn{2}{|c|}{ End Coordinates } \\
\hline & & $x$ & Y & $x$ & $Y$ \\
\hline \multicolumn{6}{|c|}{ VX Pit Grid (Cont.) } \\
\hline & 4 & 130 & 100 & 130 & 159 \\
\hline & 5 & 140 & 100 & 140 & 160 \\
\hline & 6 & 150 & 100 & 150 & 160 \\
\hline & 7 & 160 & 160 & 160 & 100 \\
\hline & 8 & 170 & 100 & 170 & 160 \\
\hline & 9 & 180 & 160 & 180 & 100 \\
\hline 1 & 0 & 180 & 80 & 180 & 160 \\
\hline 1 & 1 & 190 & 160 & 190 & 80 \\
\hline 1 & 2 & 200 & 80 & 200 & 160 \\
\hline 1 & 3 & 210 & 160 & 210 & 80 \\
\hline 1 & 4 & 220 & 80 & 220 & 160 \\
\hline 1 & 5 & 230 & 160 & 230 & 80 \\
\hline 1 & 6 & 240 & 80 & 240 & 160 \\
\hline 1 & 7 & 250 & 160 & 250 & 80 \\
\hline 1 & 8 & 260 & 80 & 260 & 157 \\
\hline 1 & 9 & 270 & 160 & 270 & 80 \\
\hline 2 & 0 & 280 & 80 & 280 & 160 \\
\hline 2 & 1 & 290 & 160 & 290 & 80 \\
\hline 2 & 2 & 300 & 80 & 300 & 160 \\
\hline 2 & 3 & 310 & 160 & 310 & 80 \\
\hline 2 & 4 & 320 & 80 & 320 & 160 \\
\hline 2 & 5 & 330 & 160 & 330 & 80 \\
\hline 2 & 6 & 340 & 100 & 340 & 160 \\
\hline 2 & 7 & 350 & 160 & 350 & 120 \\
\hline 2 & 8 & 340 & 80 & 190 & 80 \\
\hline 2 & 9 & 190 & 100 & 340 & 100 \\
\hline 3 & 0 & 350 & 120 & 190 & 120 \\
\hline 3 & 1 & 190 & 140 & 350 & 140 \\
\hline 3 & 2 & 350 & 160 & 170 & 160 \\
\hline 3 & 3 & 100 & 160 & 190 & 160 \\
\hline 3 & 4 & 190 & 140 & 100 & 140 \\
\hline 3 & 5 & 100 & 120 & 190 & 120 \\
\hline 3 & 6 & 190 & 100 & 100 & 100 \\
\hline 3 & 7 & 100 & 130 & 280 & 130 \\
\hline Riot & Control & Pit & & & \\
\hline & 1 & 300 & 100 & 300 & 160 \\
\hline & 2 & 290 & 160 & 290 & 100 \\
\hline & 3 & 280 & 100 & 280 & 160 \\
\hline
\end{tabular}


Ground Penetrating Radar Profiles (Cont.) J-Field January 1995

\begin{tabular}{|c|c|c|c|c|}
\hline \multirow[b]{2}{*}{ Profile No. } & \multicolumn{2}{|c|}{ Start Coordinates } & \multicolumn{2}{|c|}{ End Coordinates } \\
\hline & $x$ & $Y$ & $x$ & $Y$ \\
\hline Riot Control & I Pit Grid & (Cont.) & & \\
\hline 4 & 270 & 160 & 270 & 100 \\
\hline 5 & 260 & 100 & 260 & 160 \\
\hline 6 & 250 & 160 & 250 & 100 \\
\hline 7 & 240 & 100 & 240 & 160 \\
\hline 8 & 230 & 160 & 230 & 100 \\
\hline 9 & 220 & 100 & 220 & 160 \\
\hline 10 & 210 & 160 & 210 & 100 \\
\hline 11 & 200 & 100 & 200 & 150 \\
\hline 12 & 200 & 175 & 200 & 100 \\
\hline 13 & 190 & 100 & 190 & 175 \\
\hline 14 & 180 & 175 & 180 & 100 \\
\hline 15 & 170 & 100 & 170 & 160 \\
\hline 16 & 160 & 160 & 160 & 100 \\
\hline 17 & 150 & 100 & 150 & 160 \\
\hline 18 & 140 & 160 & 140 & 100 \\
\hline 19 & 100 & 100 & 275 & 100 \\
\hline 20 & 270 & 100 & 300 & 100 \\
\hline 21 & 300 & 110 & 140 & 110 \\
\hline 22 & 140 & 120 & 300 & 120 \\
\hline 23 & 300 & 130 & 140 & 130 \\
\hline 24 & 140 & 140 & 300 & 140 \\
\hline 25 & 300 & 150 & 120 & 150 \\
\hline 26 & 120 & 160 & 300 & 160 \\
\hline 27 & 200 & 175 & 180 & 175 \\
\hline 28 & 100 & 100 & 100 & 160 \\
\hline Square Pit & Grid & & & \\
\hline 1 & 170 & 240 & 170 & 100 \\
\hline 2 & 160 & 100 & 160 & 240 \\
\hline 3 & 150 & 240 & 150 & 100 \\
\hline 4 & 140 & 100 & 140 & 240 \\
\hline 5 & 130 & 240 & 130 & 100 \\
\hline 6 & 120 & 100 & 120 & 240 \\
\hline 7 & 110 & 240 & 110 & 100 \\
\hline 8 & 100 & 100 & 100 & 240 \\
\hline 9 & 110 & 240 & 110 & 100 \\
\hline 10 & 95 & 180 & 95 & 200 \\
\hline 11 & 100 & 180 & 100 & 200 \\
\hline 12 & 105 & 180 & 105 & 200 \\
\hline 13 & 100 & 240 & 170 & 240 \\
\hline 14 & 170 & 230 & 100 & 230 \\
\hline 15 & 100 & 220 & 170 & 220 \\
\hline 16 & 170 & 210 & 100 & 210 \\
\hline
\end{tabular}




\section{Ground Penetrating Radar Profiles (Cont.) J-Field January 1995}

\begin{tabular}{|c|c|c|c|c|}
\hline \multirow[b]{2}{*}{ Profile No. } & \multicolumn{2}{|c|}{ Start Coordinates } & \multicolumn{2}{|c|}{ End Coordinates } \\
\hline & $x$ & Y & $x$ & $\mathrm{Y}$ \\
\hline Square Pit & Grid $(C$ & ;ont.) & & \\
\hline 17 & 100 & 200 & 170 & 200 \\
\hline 18 & 170 & 190 & 1.00 & 190 \\
\hline 19 & 100 & 180 & 170 & 180 \\
\hline 20 & 170 & 170 & 100 & 170 \\
\hline 21 & 100 & 160 & 170 & 160 \\
\hline 22 & 170 & 150 & 100 & 150 \\
\hline 23 & 100 & 140 & 170 & 140 \\
\hline 24 & 170 & 130 & 100 & 130 \\
\hline 25 & 100 & 120 & 170 & 120 \\
\hline 26 & 170 & 110 & 100 & 110 \\
\hline 27 & 100 & 100 & 170 & 100 \\
\hline 28 & 120 & 200 & 120 & 180 \\
\hline 29 & 126 & 180 & 126 & 200 \\
\hline 30 & 133 & 200 & 133 & 180 \\
\hline 31 & 136 & 180 & 136 & 200 \\
\hline 32 & 140 & 200 & 140 & 180 \\
\hline 33 & 140 & 200 & 120 & 200 \\
\hline 34 & 120 & 195 & 140 & 195 \\
\hline 35 & 140 & 190 & 120 & 190 \\
\hline 36 & 120 & 185 & 140 & 185 \\
\hline WPP Storag & je Area & Grid & & \\
\hline 1 & 180 & 190 & 100 & 190 \\
\hline 2 & 100 & 180 & 180 & 180 \\
\hline 3 & 180 & 170 & 100 & 170 \\
\hline 4 & 100 & 160 & 177 & 160 \\
\hline 5 & 180 & 150 & 100 & 150 \\
\hline 6 & 100 & 140 & 180 & 140 \\
\hline 7 & 180 & 130 & 100 & 130 \\
\hline 8 & 100 & 120 & 180 & 120 \\
\hline 9 & 180 & 110 & 100 & 110 \\
\hline 10 & 180 & 100 & 100 & 100 \\
\hline 11 & 180 & 100 & 180 & 190 \\
\hline 12 & 170 & 190 & 170 & 100 \\
\hline 13 & 160 & 100 & 160 & 190 \\
\hline 14 & 150 & 190 & 150 & 100 \\
\hline 15 & 140 & 100 & 140 & 190 \\
\hline 16 & 130 & 100 & 130 & 190 \\
\hline 17 & 120 & 190 & 120 & 100 \\
\hline 18 & 110 & 100 & 110 & 190 \\
\hline 19 & 100 & 190 & 100 & 100 \\
\hline
\end{tabular}


Ground Penetrating Radar Profiles (Cont.) J-Field January 1995

\begin{tabular}{lcccc}
\hline & \multicolumn{3}{c}{ Exploratory Profiles } \\
\cline { 2 - 4 } & Profile No. & Start $(\mathrm{ft})$ & Finish (ft) \\
& & & & \\
Western Trench Site & 1 & 0 & 50 \\
& 2 & 0 & 50 \\
& 3 & 0 & 50 \\
Suspected Trench, Ruin Site & 1 & 0 & 50 \\
& 2 & 0 & 30 \\
Site X1 & 3 & 0 & 40 \\
& & & \\
& 1 & 0 & 50 \\
& 2 & 0 & 50 \\
& 3 & 0 & 50 \\
& 4 & 0 & 50 \\
\hline
\end{tabular}


